\title{
Dickkopf 3 Promotes the Differentiation of a Rostrolateral Midbrain Dopaminergic Neuronal Subset In Vivo and from Pluripotent Stem Cells In Vitro in the Mouse
}

\begin{abstract}
Yoshiyasu Fukusumi, ${ }^{1 *}$ - Florian Meier, ${ }^{1 *}$ Sebastian Götz, ${ }^{1 *}{ }^{\circledR}$ Friederike Matheus, ${ }^{1}$ Martin Irmler, ${ }^{2}$ Ruth Beckervordersandforth, ${ }^{3}$ Theresa Faus-Kessler, ${ }^{1}$ Eleonora Minina, ${ }^{1}{ }^{\circledR}$ Benedict Rauser, ${ }^{1}$ Jingzhong Zhang, ${ }^{1}$ Ernest Arenas, ${ }^{4}$ Elisabet Andersson, ${ }^{5}$ Christof Niehrs, ${ }^{6,7}$ Johannes Beckers, ${ }^{2,8}$ Antonio Simeone, ${ }^{9,10}$ Wolfgang Wurst, ${ }^{1,11,12,13}$ and ${ }^{-N i l i m a ~ P r a k a s h}{ }^{1,11}$

Institutes of ${ }^{1}$ Developmental Genetics and ${ }^{2}$ Experimental Genetics, Helmholtz Center Munich, German Research Center for Environmental Health, D-85764 Neuherberg, Germany, ${ }^{3}$ Emil Fischer Centre, Institute of Biochemistry, Friedrich Alexander University Erlangen-Nuremberg, D-91054 Erlangen, Germany, ${ }^{4}$ Laboratory of Molecular Neurobiology, Department of Medical Biochemistry and Biophysics and ${ }^{5}$ Department of Cell and Molecular Biology, Karolinska Institute, S-17177 Stockholm, Sweden, ${ }^{6}$ Division of Molecular Embryology, German Cancer Research Center-Center for Molecular Biology at Heidelberg University Alliance, German Cancer Research Center, D-69120 Heidelberg, Germany, ${ }^{7}$ Institute of Molecular Biology, D-55128 Mainz, Germany, ${ }^{8}$ Technical University Munich, Chair of Experimental Genetics, D-85350 Freising-Weihenstephan, Germany, ${ }^{9}$ Institute of Genetics and Biophysics “A. Buzzati-Traverso," I-80131 Naples, Italy, ${ }^{10}$ Institute for Inpatient Treatment and Scientific Studies Neuromed, I-86077 Pozzilli, Isernia, Italy, ${ }^{11}$ Technical University Munich, Chair of Developmental Genetics/Helmholtz Center Munich, D-85764 Neuherberg, Germany, ${ }^{12}$ German Center for Neurodegenerative Diseases, D-80336 Munich, Germany, and ${ }^{13}$ Munich Cluster for Systems Neurology, Adolf Butenandt Institute, Ludwig Maximilians University Munich, D-80336 Munich, Germany
\end{abstract}

Wingless-related MMTV integration site 1 (WNT1)/ $\beta$-catenin signaling plays a crucial role in the generation of mesodiencephalic dopaminergic ( $\mathrm{mdDA}$ ) neurons, including the substantia nigra pars compacta $(\mathrm{SNc})$ subpopulation that preferentially degenerates in Parkinson's disease (PD). However, the precise functions of WNT1/ $\beta$-catenin signaling in this context remain unknown. Stem cell-based regenerative (transplantation) therapies for PD have not been implemented widely in the clinical context, among other reasons because of the heterogeneity and incomplete differentiation of the transplanted cells. This might result in tumor formation and poor integration of the transplanted cells into the dopaminergic circuitry of the brain. Dickkopf 3 (DKK3) is a secreted glycoprotein implicated in the modulation of WNT/ $\beta$-catenin signaling. Using mutant mice, primary ventral midbrain cells, and pluripotent stem cells, we show that DKK3 is necessary and sufficient for the correct differentiation of a rostrolateral mdDA neuron subset. $D k k 3$ transcription in the murine ventral midbrain coincides with the onset of mdDA neurogenesis and is required for the activation and/or maintenance of LMX1A (LIM homeobox transcription factor $1 \alpha$ ) and PITX3 (paired-like homeodomain transcription factor 3 ) expression in the corresponding mdDA precursor subset, without affecting the proliferation or specification of their progenitors. Notably, the treatment of differentiating pluripotent stem cells with recombinant DKK3 and WNT1 proteins also increases the proportion of mdDA neurons with molecular SNc DA cell characteristics in these cultures. The specific effects of DKK3 on the differentiation of rostrolateral mdDA neurons in the murine ventral midbrain, together with its known prosurvival and anti-tumorigenic properties, make it a good candidate for the improvement of regenerative and neuroprotective strategies in the treatment of PD.

Key words: differentiation; DKK3; mouse; stem cell; substantia nigra dopamine neuron; WNT1

Significance Statement

We show here that Dickkopf 3 (DKK3), a secreted modulator of WNT (Wingless-related MMTV integration site)/ $\beta$-catenin signaling, is both necessary and sufficient for the proper differentiation and survival of a rostrolateral (parabrachial pigmented nucleus and dorsomedial substantia nigra pars compacta) mesodiencephalic dopaminergic neuron subset, using Dkk3 mutant mice and murine primary ventral midbrain and pluripotent stem cells. The progressive loss of these dopamine-producing mesodiencephalic neurons is a hallmark of human Parkinson's disease, which can up to now not be halted by clinical treatments of this disease. Thus, the soluble DKK3 protein might be a promising new agent for the improvement of current protocols for the directed differentiation of pluripotent and multipotent stem cells into mesodiencephalic dopaminergic neurons and for the promotion of their survival in situ. 


\section{Introduction}

Dopamine (DA)-synthesizing neurons located in the mammalian ventral midbrain (VM) play crucial roles in the control and modulation of motor, motivational/rewarding, and cognitive behaviors (Schultz, 2007). They comprise two major subpopulations: (1) a rostrolateral bilateral cluster, the substantia nigra pars compacta (SNc); and (2) a caudomedial cluster, the ventral tegmental area (VTA) (Björklund and Dunnett, 2007). The SNc DA neurons project predominantly to the dorsolateral striatum, in which they control the execution of voluntary movements (Björklund and Dunnett, 2007; Schultz, 2007). The preferential degeneration of these neurons is a hallmark of Parkinson's disease (PD; Dauer and Przedborski, 2003). The need of better therapies for this disease has fueled basic research to understand the precise molecular mechanisms underlying the generation and survival of SNc DA neurons (Arenas, 2010).

During mouse development, the progenitors of these "mesodiencephalic" dopaminergic (mdDA) neurons arise from the ventral midline, the floor plate (FP), of the midbrain and caudal diencephalon under the influence of the Sonic hedgehog $(\mathrm{SHH})$, Wingless-related MMTV integration site 1 (WNT1), and fibroblast growth factor 8 (FGF8) signaling pathways (Ono et al., 2007; Bonilla et al., 2008; Joksimovic et al., 2009; Blaess et al., 2011; for review, see Hegarty et al., 2013). SHH is necessary for the establishment of the mesencephalic FP and basal plate (BP) progenitor domains between embryonic day 8.5 (E8.5) and E9.5 (Blaess et al., 2006; Perez-Balaguer et al., 2009), but its expression has to be repressed by $\mathrm{WNT} / \beta$-catenin signaling to convey mdDA neurogenic potential to the midbrain FP cells at approximately E11.5 (Joksimovic et al., 2009). The in vivo generation of mdDA neurons depends crucially on WNT1 and its downstream $(\beta$ catenin-mediated) signaling pathway (Prakash et al., 2006; Tang et al., 2009), although increasing evidence indicates that WNT1/ $\beta$-catenin signaling must be tightly regulated to ensure proper mdDA neuron differentiation (Joksimovic et al., 2009; Tang et al., 2010; Andersson et al., 2013). The secreted Dickkopf (DKK1DKK4) glycoproteins are one class of $\mathrm{WNT} / \beta$-catenin signaling modulators (Niehrs, 2006). DKK1/2/4 antagonize WNT/ $\beta$ catenin signaling by binding to low-density lipoprotein receptorrelated protein (LRP) and Kremen coreceptors and inducing their internalization, thereby inhibiting the formation of an ac-

Received May 3, 2015; revised Aug. 17, 2015; accepted Aug. 21, 2015.

Author contributions: W.W. and N.P. designed research; Y.F., F.Me., S.G., F.Ma., M.I., R.B., E.M., and B.R. performed research; J.Z., E.An., and C.N. contributed unpublished reagents/analytic tools; Y.F., F.Me., S.G., M.I., R.B., T.F.-K., E.Ar., J.B., A.S., and N.P. analyzed data; N.P. wrote the paper.

This work was supported by Italian Association for Cancer Research Grant IG2013 (A.S.), the German Research Foundation within the framework of the Munich Cluster for Systems Neurology (EXC 1010 SyNergy), the Bavarian State Ministry for Education and Culture, Science, and Art within the Bavarian Research Network "Human Induced Pluripotent Stem Cells," and the Systems Biology of Stem Cells and Reprogramming Project, which received funding from the European Union Seventh Framework Programme for Research, Technological Development, and Demonstration under Grant Agreement FP7-HEALTH-F4-2010-242129 (W.W.). We are particularly grateful to Prof. C. Birchmeier-Kohler and Dr. T. Müller for kindly providing the LMX1B antibody and to Prof. M. Li for providing the Pitx ${ }^{G F P /+}$ mice. We thank Dr. M. Endele for help with the FACS of VM cells and A. Bettenbrock, A. Folchert, and S. Badeke for excellent technical assistance. The monoclonal En1 antibody was obtained through the Developmental Studies Hybridoma Bank under the auspices of the National Institute of Child Health and Human Development and maintained by the University of lowa (lowa City, IA).

The authors declare no competing financial interests.

*Y.F., F.Me., and S.G. contributed equally to this work.

Correspondence should be addressed to either of the following: Wolfgang Wurst, Institute of Developmental Genetics, Helmholtz Center Munich, German Research Center for Environmental Health, and Technical University Munich, Chair of Developmental Genetics, Ingolstädter Landstrasse 1, D-85764 Neuherberg, Germany, E-mail: wurst@helmholtz-muenchen.de; or Nilima Prakash, Hamm-Lippstadt University of Applied Sciences, Marker Allee 76-78, D-59063 Hamm, Germany, E-mail: nilima.prakash@hshl.de.

DOI:10.1523/JNEUROSCI.1722-15.2015

Copyright $\odot 2015$ the authors $\quad 0270-6474 / 15 / 3513386-17 \$ 15.00 / 0$
Table 1. Primer and PCR conditions used for genotyping, semi-qPCR, and $q P C R$

\begin{tabular}{|c|c|c|c|c|}
\hline Gene (application) & $\operatorname{Primer}\left(5^{\prime} \rightarrow 3^{\prime}\right)$ & $\begin{array}{l}\text { Product } \\
\text { length (bp) }\end{array}$ & $\operatorname{Tm}\left({ }^{\circ} \mathrm{C}\right)$ & Cycles \\
\hline GFP (genotyping) & $\begin{array}{l}\text { Forward, CCATGGTGAGCAAGGGCGA } \\
\text { Reverse, CTCGAGCTTGTACAGCTCGTCCATG }\end{array}$ & 800 & 60 & 35 \\
\hline Pitx3 (genotyping) & $\begin{array}{l}\text { Forward, GGAGTTTGGGCTGCTTGGTG } \\
\text { Reverse, CCACACCGCGATCTCTTCG }\end{array}$ & 512 & 60 & 35 \\
\hline Sry (genotyping) & $\begin{array}{l}\text { Forward, GAGAGCATGGAGGGCCAT } \\
\text { Reverse, CCACTCCTCTGTGACACT }\end{array}$ & 282 & 62 & 30 \\
\hline Lmx1a (semi-qPCR) & $\begin{array}{l}\text { Forward, ACCAACAGAACACCCAGAGG } \\
\text { Reverse, CTTCTGAGGTTGCCAGGAAG }\end{array}$ & 285 & 62 & * \\
\hline $\operatorname{Lm} \times 1 b(\mathrm{qPCR})$ & $\begin{array}{l}\text { Forward, CACTTGGGCTGTTTCTGCTG } \\
\text { Reverse, TTGAAAGCTCTTCGCTGCTG }\end{array}$ & 296 & 60 & * \\
\hline $\begin{array}{l}\text { Gapdh (semi-qPCR, } \\
\qquad q P(R)\end{array}$ & $\begin{array}{l}\text { Forward, ACCACAGTCCATGCCATCAC } \\
\text { Reverse, TCCACCACCCTGTTGCTGTA }\end{array}$ & 452 & 59 & $30^{*}$ \\
\hline
\end{tabular}

${ }^{*}$ As indicated in Materials and Methods for semi-qPCR and qPCR.

tive WNT/Frizzled receptor (FZD)/LRP coreceptor complex on the cell surface (Niehrs, 2006). The function of the more distantly related DKK3 remains unresolved (Niehrs, 2006; Veeck and Dahl, 2012): DKK3 does not bind to LRP6 and can act as both a repressor and activator of $\mathrm{WNT} / \beta$-catenin signaling (Nakamura et al., 2007; Nakamura and Hackam, 2010; Das et al., 2013; Xiang et al., 2013). The importance of the WNT1/ $\beta$-catenin signaling pathway in this context has also been recognized in recent years for the derivation of mdDA neurons from in vitro cultured murine and human pluripotent stem cells (PSCs), including embryonic stem cells (ESCs) and induced PSCs (iPSCs). Exposure of differentiating ESCs and iPSCs to WNT1 or a glycogen synthase kinase $3 \beta$ (GSK3b) inhibitor is now incorporated routinely in established mdDA differentiation protocols for human PSCs, which can be used for PD modeling, drug screening, and cellreplacement therapies (Yu et al., 2013; for review, see Li et al., 2013; Tabar and Studer, 2014).

We show here that $D k k 3$ is necessary for the correct differentiation of an mdDA precursor subset into rostrolateral (dorsomedial SNc and dorsolateral VTA) mdDA neurons in the mouse embryo. DKK3 appears to activate and/or maintain the expression of LIM homeobox transcription factor $1 \alpha$ (LMX1A) and paired-like homeodomain transcription factor 3 (PITX3) in these cells, two homeodomain (HD) transcription factors (TFs) required for the proper generation and survival of mdDA and in particular SNc DA neurons (for review, see Smidt and Burbach, 2007; Hegarty et al., 2013). We also show that the treatment of differentiating murine PSCs with DKK3 and WNT1 proteins promotes the generation of mdDA neurons with molecular SNc DA cell characteristics in vitro, suggesting that DKK3 might be an additional candidate for the improvement of cell differentiation strategies in the treatment of PD.

\section{Materials and Methods}

Mice. Generation and genotyping of $D k k 3^{-1-}$ mice was described previously (del Barco-Barrantes et al., 2006). Generation of Pit $x 3^{G F P /+}$ mice was described by Zhao et al. (2004); these mice were PCR genotyped using the green fluorescent protein (GFP) and Pitx3 primer pairs listed in Table 1. $D k k 3^{+/+}, D k k 3^{+/-}$, and $D k k 3^{-/-}$mice were kept as brothersister matings on a mixed $(129 \mathrm{X} 1 / \mathrm{SvJ} \times \mathrm{C} 57 \mathrm{BL} / 6)$ genetic background. Pitx $3^{\text {GFP/+ }}$ embryos were derived from Pitx $3^{\text {GFP/GFP }}$ (on a mixed 129P2/ OlaHsd $\times$ C57BL/6 background) $\times$ C57BL/6 intercrosses. CD -1 and C57BL/6 mice were provided by the Transgenic Unit, Helmholtz Center Munich. Pregnant dams were killed by $\mathrm{CO}_{2}$ asphyxiation or cervical dislocation. Collection of embryonic stages was done from timedpregnant females; noon of the day of vaginal plug detection was designated as E0.5. Detection of the Y chromosome-specific Sry gene by 
genomic PCR (Table 1) was used for embryonic sex determination. Dkk3 mutant embryos of either sex were compared with their wild-type (WT; $D k k 3^{+/+}$and $\left.D k k 3^{+/-}\right)$littermates, and at least three embryos were analyzed for each probe, genotype, and stage, if not indicated otherwise. This study was performed in strict accordance with the recommendations in the European Union Directive 2010/63/EU and the Guide for the Care and Use of Laboratory Animals of the Federal Republic of Germany (German Animal Protection Law). The protocol was approved by the Institutional Animal Care and Use Committee (Committee for Animal Experiments and Laboratory Animal Facility) of the Helmholtz Center Munich. All efforts were made to minimize suffering.

5-Ethynyl-2'-deoxyuridine treatments. Embryos were dissected $1 \mathrm{~h}$ after intraperitoneal injection of $10 \mu \mathrm{g}$ of 5-ethynyl-2'-deoxyuridine (EdU; Life Technologies) per gram body weight into pregnant dams on E11.5. Treated embryos were processed for EdU immunohistochemistry (IHC) as described previously (Castelo-Branco et al., 2010), and incorporated EdU was detected using the Click-iT EdU Alexa Fluor 488 imaging kit (Life Technologies) according to the instructions of the manufacturer.

Radioactive in situ hybridization. Serial paraffin sections $(8 \mu \mathrm{m})$ were hybridized with radioactive $\left(\left[\alpha^{-}{ }^{35} \mathrm{~S}\right] \mathrm{UTP}\right)$ riboprobes as described previously (Brodski et al., 2003). Riboprobes used were Dkk1, Dkk2, and Dkk3 (Monaghan et al., 1999), tyrosine hydroxylase (Th) and Pitx3 (Brodski et al., 2003), Wnt1 and Lmx1b (Stuebner et al., 2010), Fgf8, Engrailed 1 (En1), Shh, Neurog1 (Ngn1), and Neurog2 (Ngn2) (CasteloBranco et al., 2010). Images were taken with an Axioplan2 microscope or StemiSV6 stereomicroscope using bright-field and dark-field optics, AxioCam MRc camera and Axiovision 4.6 software (Zeiss), and processed with Adobe Photoshop CS3 software (Adobe Systems). Dark-field images were pseudocolored in some cases as indicated in the figure legends.

Immunohistochemistry/immunocytochemistry. IHC on $8 \mu \mathrm{m}$ paraffin sections and immunocytochemistry (ICC) on cultured cells were performed as reported previously (Puelles et al., 2004; Peng et al., 2011). Monoclonal antibodies used were mouse anti-TH (1:600; Millipore MAB318), anti-EN1 (1:100; Developmental Studies Hybridoma Bank 4G11), and rat anti-dopamine transporter (DAT, also known as SLC6A3; 1:500; Millipore MAB369). Polyclonal antisera used were rabbit anti-TH (1:150; Millipore AB152; 1:1000; Pel_Freeze P40101), anti-PITX3 (1:300; Life Technologies 38-2850), anti-LMX1A (1:1000; Millipore ab10533), anti-phosphorylated Histone H3 (pH3) (1:500; Millipore 06-570), anticleaved (activated) Caspase 3 (cCASP3; 1:100; Cell Signaling Technology 9664), anti-nuclear receptor subfamily 4, group A, member 2 (NURR1, also known as NR4A2; 1:2000; Santa Cruz Biotechnology sc-990), anticalbindin 1 [CALB1; 1:400 (embryos) and 1:5000 (cell cultures); Swant CB38a], anti-potassium voltage-gated channel, ShaI-related family, member 3 (KCND3, also known as Kv4.3; 1:2000; Alomone Labs APC-017), and antipotassium inwardly rectifying channel, subfamily J, member 6 (KCNJ6, also known as GIRK2; 1:2000; Alomone Labs APC-006). The guinea pig antiLMX1B antibody (1:20,000) was a gift from Prof. C. Birchmeier-Kohler and Dr. T. Müller (Max Delbrück Center, Berlin, Germany). Secondary antibodies were either fluorescently labeled (Alexa Fluor 488/594; 1:500; Life Technologies) or coupled to biotin/streptavidin-horseradish peroxidase or alkaline phosphatase (AP; Jackson ImmunoResearch) and detected using the VECTASTAIN ABC or VECTOR Red AP Substrate kits (Vector Laboratories). Cells were counterstained with 4',6-diamidino-2-phenylindole (DAPI). Fluorescent images were taken with an Axiovert 200M microscope and AxioCam HRc camera (Zeiss), a Keyence BZ-9000 microscope, or an Olympus IX81 confocal laser scanning microscope and processed with Adobe Photoshop CS3 or CS5 software. For the simultaneous detection of TH protein and Dkk3 mRNA on embryonic tissue sections, the Dkk3 in situ hybridization (ISH) was preceded by a TH IHC as described above, leaving out all extensive ethanol washes.

Primary VM cultures and DKK3/EdU treatments. Primary VM cultures were prepared from E11.5 Dkk3 ${ }^{+/+}$(WT) and $D k k 3^{-/-}$mouse embryos as described by Pruszak et al. (2009) with minor modifications. Briefly, VM tissues were trypsinized for $5 \mathrm{~min}$ at $37^{\circ} \mathrm{C}$, and $1.5-2 \times 10^{5}$ cells per well were plated in a 24 -well plate on poly-D-lysine (Sigma)-coated coverslips in DMEM/F-12 medium supplemented with $10 \%$ fetal calf serum
(FCS), glutamine, and penicillin/streptomycin (Life Technologies). At $24 \mathrm{~h}$ after plating, cells were incubated in expansion medium for $1 \mathrm{~d}$ and then switched to differentiation medium (Pruszak et al., 2009) for the remaining culture time. Concomitant with the change to differentiation medium after $2 \mathrm{~d}$ in vitro ( $2 \mathrm{DIV}$ ), primary VM cells were treated with $100 \mathrm{ng} /$ well recombinant human DKK3 protein [R\&D Systems; 100 $\mathrm{ng} / \mu \mathrm{l}$ DKK3 in $0.1 \%$ bovine serum albumin (BSA; Sigma)] or $1 \mu \mathrm{g} /$ well BSA (control; $1 \mu \mathrm{g} / \mu \mathrm{l}$ ) for the indicated time. DKK3 or BSA was added with each medium change every fourth day. In some cases, cells were incubated with $10 \mu \mathrm{M}$ EdU for $1 \mathrm{~h}$ before fixation. Cells were harvested for ICC or RNA isolation after $4 \mathrm{~d}$ (6 DIV) or $7 \mathrm{~d}$ (9 DIV) of treatments.

ESC/iPSC culture and differentiation into mdDA neurons. Generation, characterization, and culture of Pitx $3^{\text {GFP/+ }}{ }^{\text {PSSC }^{t f}}$ S (line FM77A3) were described previously (Pertek et al., 2014). Pitx $3^{\text {GFP/+ }}$ iPSC $^{\text {tf }}$ S were cultured on mitomycin-C treated mouse embryonic fibroblasts (MEFs) in ESC medium before initiating their differentiation into mdDA neurons using a monolayer differentiation protocol that was adapted from published procedures for mouse and human PSCs (Chambers et al., 2009; Jaeger et al., 2011; Kriks et al., 2011). On day 0 of the differentiation procedure, cells were trypsinized, and $1.4 \times 10^{4}$ cells $/ \mathrm{cm}^{2}$ were transferred to tissue culture dishes in serum replacement medium (SRM; DMEM/F-12 GlutaMAX, 10\% KnockOut Serum Replacement, and $0.1 \mathrm{~mm} \beta$-mercaptoethanol; Life Technologies) containing $10 \mu \mathrm{m}$ Rhodependent protein kinase inhibitor Y-27632 (4-[(1R)-1-aminoethyl]-Npyridin-4-yl-cyclohexane-1-carboxamide) (Calbiochem). After incubation for $50 \mathrm{~min}$ at $37^{\circ} \mathrm{C}$, the cell supernatant was plated at a density of $1.4 \times$ $10^{4}$ cells $/ \mathrm{cm}^{2}$ on poly-DL-ornithine-coated $(0.1 \mathrm{mg} / \mathrm{ml}$ in $300 \mathrm{~mm}$ borate buffer, pH 8.3; Sigma) and laminin-coated (125 $\mu \mathrm{g} / \mathrm{ml}$ in PBS; Roche) coverslips in SRM containing $10 \mu \mathrm{M}$ transforming growth factor $\beta$ (TGF $\beta$ ) type I receptor [activin receptor-like kinase (ALK) 4/5/7] inhibitor SB431542 [4-(4-(benzo[d] [1,3] dioxol-5-yl)-5-(pyridin-2-yl)- $1 \mathrm{H}$ imidazol-2-yl)benzamide] (SB; in DMSO; Tocris Bioscience) and $100 \mathrm{nM}$ bone morphogenetic protein type I receptor (ALK1/2/3/6) inhibitor LDN193189 [4-(6-(4-(piperazin-1-yl)phenyl)pyrazolo[1,5-a]pyrimidin-3yl)quinoline] (LDN; in DMSO; Axon Medchem) to suppress alternative mesodermal, endodermal, and epidermal cell fates. On day 1 , the medium was changed to $50 \%$ SRM $/ 50 \% \mathrm{~N} 2$ medium [DMEM/F-12 GlutaMAX, $1 \times$ N2 supplement (Life Technologies) and $200 \mu \mathrm{M}$ ascorbic acid (Sigma)] containing $10 \mu \mathrm{M} \mathrm{SB}, 100 \mathrm{~nm} \mathrm{LDN}$, and $1 \mu \mathrm{M}$ mitogenactivated protein kinase kinase inhibitor PD0325901 [(R)-N-(2,3dihydroxypropoxy)-3,4-difluoro-2-((2-fluoro-4-iodophenyl)amino) benzamide] (in DMSO; Stemgent) to promote the VM neural fate. On day 3, differentiation of the Pitx $3^{G F P /+}$ iPSC $^{\text {tf }}$ s into mdDA neurons was initiated by treating the cells for $4 \mathrm{~d}$ with N2 medium containing $200 \mu \mathrm{M}$ ascorbic acid, $10 \mu \mathrm{M} \mathrm{SB}, 100 \mathrm{~nm} \mathrm{LDN}$, and $100 \mathrm{ng} / \mathrm{ml}$ recombinant mouse FGF8b (R\&D Systems) either alone or together with $3 \mu \mathrm{M}$ GSK3b inhibitor CHIR99021 [6-((2-((4-(2,4-dichlorophenyl)-5-(5-methyl-1Himidazol-2-yl)-2 pyrimidinyl)amino)ethyl)amino)-3-pyridinecarbonitrile] (CHIR99; in DMSO; Stemgent), $100 \mathrm{ng} / \mathrm{ml}$ recombinant human DKK3 (R\&D Systems), and/or $100 \mathrm{ng} / \mathrm{ml}$ recombinant human WNT1 (Peprotech), as indicated. On day 5, the medium was changed to N2B27 medium $(50 \% \mathrm{~N} 2,50 \% 1 \times$ B27 supplement in Neurobasal medium, 2 mM L-glutamine, and $200 \mu \mathrm{M}$ ascorbic acid; Life Technologies) containing $100 \mathrm{~nm} \mathrm{LDN}$ and $100 \mathrm{ng} / \mathrm{ml}$ FGF8b either alone or together with $3 \mu \mathrm{M}$

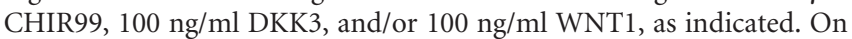
day 7 , the medium was replaced with B27 medium containing $200 \mu \mathrm{M}$ ascorbic acid, $100 \mathrm{nM} \mathrm{LDN}$ and $3 \mu \mathrm{M}$ CHIR99, $100 \mathrm{ng} / \mathrm{ml}$ DKK3, and/or $100 \mathrm{ng} / \mathrm{ml} \mathrm{WNT1}$, as indicated. The LDN inhibitor was omitted from day 9 onward. Omission of the WNT/ $\beta$-catenin signaling factors (CHIR99, DKK3, and/or WNT1) was used as a control. Addition of $20 \mathrm{ng} / \mathrm{ml} \mathrm{re-}$ combinant human brain-derived neurotrophic factor (BDNF; R\&D Systems) to B27 medium containing $200 \mu \mathrm{M}$ ascorbic acid from day 11 promoted the maturation and survival of the generated Pitx $3^{G F P /+}$ mdDA neurons, which were analyzed routinely on day 21 .

Unbiased stereology and cell countings. For IHC, $\mathrm{TH}^{+}$and PITX3 ${ }^{+}$ single-labeled cells in WT and $D k k 3^{-1-}$ brains were evaluated on every fourth (E12.5), sixth (E14.5), or eighth (E18.5 and adult) serial coronal or horizontal midbrain section by the optical fractionator method using 
Stereo Investigator 5.05.4 software (MBF Bioscience). Single- and double-labeled cells were counted on every fourth $\left(\mathrm{TH}^{+} / \mathrm{PITX}^{+}\right.$, $\mathrm{TH}^{+} / \mathrm{LMX} \mathrm{A}^{+}, \mathrm{LMX} \mathrm{A}^{+} / \mathrm{EdU}^{+}$, or $\mathrm{pH}^{+}$cells) or eighth $\left(\mathrm{TH}^{+} /\right.$ cCASP $3^{+}$or $\mathrm{TH}^{+} / \mathrm{CALB} 1^{+}$cells) coronal midbrain section from E10.5, E11.5, E12.5, E14.5, or E18.5 WT and $D k k 3^{-1-}$ embryos using Stereo Investigator 5.05.4 software. For ICC on primary VM cells, $\mathrm{TH}^{+}$, $\mathrm{PITX}^{+}, \mathrm{EdU}^{+}, \mathrm{pH}^{+}{ }^{+}$, and cCASP $3^{+}$single- or double-labeled cells were counted in 10 random fields per coverslip. For ICC on differentiating PSCs, $\mathrm{TH}^{+} / \mathrm{PITX}^{+}$double-labeled cell clusters and $\mathrm{TH}^{+}, \mathrm{PITX}^{+}$, and NR4A2 ${ }^{+}$single- and double-labeled cells within double-positive cell clusters were counted on one coverslip and normalized to cluster area using Stereo Investigator 5.05.4 software. The proportion of $\mathrm{TH}^{+} /$ $\mathrm{PITX}^{+}{ }^{+}, \mathrm{TH}^{+} / \mathrm{NR}_{4 A 2}{ }^{+}, \mathrm{TH}^{+} / \mathrm{CALB}{ }^{+}$, and $\mathrm{TH}^{+} / \mathrm{KCND}^{+}{ }^{+}$doublelabeled cells among the total number of $\mathrm{TH}^{+}$cells was determined for at least three clusters per coverslip. $\mathrm{TH}^{+} / \mathrm{KCND}^{+}$double-labeled cells were counted on confocal images using Olympus Fluoview version $2.0 \mathrm{~b}$ software. The numbers $(n)$ of independent experiments evaluated in each case are indicated in the figure legends.

Semiquantitative and quantitative RT-PCR. Total RNA was isolated from primary VM cells using TRIzol Reagent (Life Technologies) or RNeasy Mini kit (Qiagen) including a DNase I treatment. One microgram of total RNA was reverse transcribed using the iScript cDNA Synthesis kit [Bio-Rad; for semiquantitative (semi-q) PCR] or QuantiTect Reverse Transcription kit [Qiagen; for quantitative (q) PCR] according to the instructions of the manufacturer. One microliter (semi-qPCR) or $1 \mu \mathrm{l}$ of a 1:3 diluted (qPCR) cDNA were amplified by PCR using the intron-spanning primers and conditions listed in Table 1. For semiqPCR, $5 \mu \mathrm{l}$ samples were taken from the PCR reactions after 22, 25, 28, 31 , and 34 cycles and separated on a $2 \%$ agarose gel. Densitometric analysis of the gel pictures was done using NIH ImageJ software. The qPCR (20 $\mu \mathrm{l}$ reactions in a 384-well plate) was performed using SYBR green PCR Master Mix and the 7900HT Fast Real-Time PCR System (Applied Biosystems) according to the instructions of the manufacturer. For semi-qPCR and qPCR, signals from specific $L m \times 1 a$ and $L m \times 1 b$ PCR products were normalized against glyceraldehyde-3-phosphate dehydrogenase (Gapdh), and relative values were calculated by setting the normalized value of controls as 1 . For qPCR, the threshold cycle $(\mathrm{Ct})$ value was recorded for $L m x l b$ and Gapdh, and the relative Ct value was calculated for each reaction. All assays included negative controls, and samples were from three independent experiments.

Fluorescence-activated cell sorting and global transcriptome analysis. Single-cell suspensions from microdissected VM tissues of E13.5 and E14.5 Pit $3^{\text {GFP/+ }}$ embryos (one biological sample each) were prepared as described previously (Zhao et al., 2004). Differentiated Pitx3 ${ }^{G F P /+}$ iPSC $^{\text {tf }} \mathrm{S}$ (days 19-23 of the monolayer protocol; five biological replicates/ independent experiments) were trypsinized, filtered through a $70 \mu \mathrm{m}$ cell strainer, pelleted, and resuspended in ice-cold PBS. Fluorescenceactivated cell sorting (FACS) of $\mathrm{GFP}^{+}$cells was performed with a FACSAria III (BD Biosciences) device essentially as described previously (Fischer et al., 2011; Pertek et al., 2014). Sorted cells were collected directly in RLT buffer, and total RNA was purified with the RNeasy Micro kit (Qiagen), including a DNase I treatment and following the instructions of the manufacturer. The quality of the purified total RNA was assessed with the RNA 6000 Pico kit and 2100 Bioanalyzer (Agilent). Total RNA ( $\sim 1 \mathrm{ng}$ ) was amplified using the Ovation PicoSL WTA System V2 in combination with the Encore Biotin Module (Nugen). Amplified cDNAs were hybridized on Affymetrix Mouse Gene 1.0 ST arrays containing $\sim 28,000$ probe sets. Staining and scanning was done according to the Affymetrix expression protocol including minor modifications as suggested in the Encore Biotin protocol. Expression console (version 1.2; Affymetrix) was used for quality control and to obtain annotated normalized robust multi-array average gene-level data (standard settings including median polish and sketch-quantile normalization). Statistical analyses were performed with R software (http://www.R-project.org) implemented in CARMAweb (Rainer et al., 2006). Gene-wise testing for differential expression was done using the limma paired $t$ test and Benjamini-Hochberg multiple testing correction (false discovery rate $<10 \%$ ). The set of 460 probe sets was defined by $p<0.05$ ( $p$ value of the limma $t$ test), ratios $>1.2$-fold up or down, and an average expression level $>50$. Heat maps were generated with CARMAweb and cluster dendrograms with the R script hclust. Gene Ontology (GO) term enrichment analyses $(p<0.01)$ were done with GePS software (Genomatix). Array data have been submitted to GEO (accession number GSE58813).

Statistical analyses. All values are mean \pm SEM unless indicated otherwise. Cell numbers were averaged for each genotype, stage, sex, region, and/or treatment and subjected to tests for the estimation of statistical significance relative to the control. For comparison of two groups, the Welsh $t$ test for unequal variances was applied. The effect of experimental factors with more than two levels and the effect of two or more experimental factors were analyzed with one-way, two-way, or three-way ANOVA, depending on the number of factors. In the case of two or more factors, the analysis started with an ANOVA with the highest possible interaction effect and excluded stepwise nonsignificant interactions to identify the simplest model. For factors involved in a significant interaction effect, subgroups were analyzed separately. Post hoc $t$ tests were performed with $p$ value adjustment according to Holm (1979). For cell countings with several sections per embryo and for semi-qPCR and qPCR, ANOVA for repeated measurements was applied. For all calculations, the R software with the nlme package was used.

\section{Results}

Dkk3 expression in the murine VM coincides with the initiation of mdDA neuron differentiation and persists in adulthood

To establish a potential role of DKK3 in murine mdDA neuron development, we first determined the spatiotemporal pattern of $D k k 3$ expression in the developing mouse VM in relation to two other $D k k$ family members, $D k k 1$ and $D k k 2$, and two markers for differentiating mdDA neurons, the mdDA-specific HD TF Pitx3 and $T h$, the rate-limiting enzyme for DA biosynthesis (Smidt and Burbach, 2007). The strong expression of Dkk1 and Dkk2 in the midbrain FP at E10.5 (Fig. $1 A-C$ ) declined at E11.5 (Monaghan et al., 1999; Ribeiro et al., 2011) and became undetectable at E12.5 (Fig. $1 E-G$ ). In contrast, a weak $D k k 3$ signal was first detected at E11.5 in the medial FP of the rostral midbrain (Fig. $1 D, D^{\prime}, H$ ). This $D k k 3^{+}$domain extended into the lateral FP and the BP in the caudal midbrain (Fig. $1 \mathrm{H}^{\prime}$ ) and overlapped with the $\mathrm{Th}^{+}$domain along the anterior-posterior axis of the VM (Fig. $\left.1 I-I^{\prime \prime \prime}\right)$. At E12.5, $D k k 3$ expression in the VM was confined to the midbrain FP, in which it was transcribed in the Pitx $3^{-}$ventricular and subventricular zone (VZ/SVZ) and in a mantle zone (MZ) domain overlapping with Pit $3^{+}$mdDA precursors and neurons (Fig. $1 J$ ). At E14.5, Dkk3 was expressed in a very narrow FP domain from which Pit $^{+} 3^{+}$mdDA precursors/neurons emerged (Fig. 1L). A weak expression of $D k k 3$ became evident within a lateral $\mathrm{Th}^{+}$ domain at E15.5 (Fig. $1 K-K^{\prime \prime \prime}$ ). At E18.5 and in the adult mouse brain, $D k k 3$ transcription was detected in a rostrolateral $\mathrm{Th}^{+}$and Pit $3^{+}$mdDA domain comprising the parabrachial pigmented nucleus (PBP), part of the medial and dorsal SNc, and the paranigral nucleus, but the majority of the $D k k 3^{+}$cells were located outside of this mdDA domain (Fig. $\left.1 M-R^{\prime \prime \prime}\right)$. Of note, highermagnification views revealed that some $\mathrm{TH}^{+}$and $\mathrm{Pitx}^{+}$cells coexpressed $D k k 3$ in these regions (Fig. $1 N-Q$, inset in $N^{\prime \prime}$ ). We concluded that $D k k 3$ was expressed initially (at E11.5-E15.5) in mdDA progenitors and precursors located in the VZ/SVZ and $\mathrm{MZ}$ of the midbrain FP and later (after E15.5 into adulthood) in an mdDA neuronal subset comprising mostly the PBP, part of the dorsomedial SNc, and the paranigral nucleus.

\section{Defective differentiation of rostrolateral mdDA neurons in Dkk $3^{-/-}$mice}

The peculiar Dkk3 expression pattern in the murine VM suggested a potential function of DKK3 in mdDA neuron development and/or survival in vivo. The transcription of genes required 




Figure 1. Dkk3 expression in the murine VM initiates with mdDA neuron differentiation and persists into adulthood. $\boldsymbol{A}-\boldsymbol{R}^{\prime \prime \prime}$, Representative close-up views of the VM $\left(\boldsymbol{A}-\boldsymbol{H}^{\prime}, \boldsymbol{I}^{\prime}-\boldsymbol{J}, \boldsymbol{K}^{\prime}-\boldsymbol{L}, \boldsymbol{M}^{\prime}-\boldsymbol{Q}\right.$, $\left.\boldsymbol{R}^{\prime}-\boldsymbol{R}^{\prime \prime \prime}\right)$ and brain overviews $(\boldsymbol{I}, \boldsymbol{K}, \boldsymbol{M}, \boldsymbol{R})$ on cresyl violet-stained coronal $\left(\boldsymbol{A}-\boldsymbol{H}^{\prime}, \boldsymbol{J}-\mathbf{Q}\right.$; dorsal top) and sagittal $\left(\boldsymbol{I}-\boldsymbol{I}^{\prime \prime}, \boldsymbol{R}-\boldsymbol{R}^{\prime \prime \prime} ;\right.$ anterior left) sections (coronal and sagittal level indicated by broken lines in $\boldsymbol{I}$ and $\boldsymbol{K}$, respectively) from WT embryos at E10.5 $\left(\boldsymbol{A}-\boldsymbol{D}^{\prime}\right)$, E11.5 $\left(\boldsymbol{H}-\boldsymbol{I}^{\prime \prime \prime}\right)$, E12.5 $(\boldsymbol{E}-\mathbf{G}, \boldsymbol{J})$, E14.5 $(\boldsymbol{L}), \mathrm{E} 15.5\left(\boldsymbol{K}-\boldsymbol{K}^{\prime \prime \prime}\right)$, E18.5 $(\boldsymbol{M}-\boldsymbol{Q})$ and adult brains $\left(\boldsymbol{R}-\boldsymbol{R}^{\prime \prime \prime}\right)$, hybridized with riboprobes for $D k k 1(\boldsymbol{B}$,

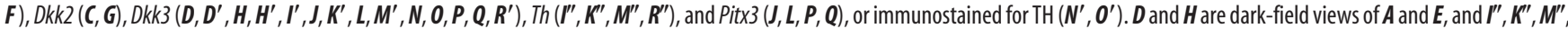
and $\boldsymbol{R}^{\prime \prime}$ are higher-magnification dark-field views of the boxed areas in $\boldsymbol{I}, \boldsymbol{K}, \boldsymbol{M}$, and $\boldsymbol{R}$, respectively. $\boldsymbol{D}, \boldsymbol{D}^{\prime}, \boldsymbol{H}, \boldsymbol{H}^{\prime}$, and $\boldsymbol{N}$ - $\mathbf{Q}$ are different rostrocaudal levels of the $V M$. $\boldsymbol{I}^{\prime \prime}, \boldsymbol{J}, \boldsymbol{K}^{\prime \prime \prime}, \boldsymbol{L}, \boldsymbol{M}^{\prime \prime \prime}, \boldsymbol{P}, \boldsymbol{Q}, \boldsymbol{a n d}^{\prime} \boldsymbol{R}^{\prime \prime \prime}$ are pseudocolored overlays of consecutive sections hybridized with $D k k 3$ (red) and Th (green in $\boldsymbol{I}^{\prime \prime \prime}, \boldsymbol{K}^{\prime \prime \prime}, \boldsymbol{M}^{\prime \prime \prime}, \boldsymbol{R}^{\prime \prime \prime}$ ) or Pitx3 (green in $\boldsymbol{J}, \mathbf{L}, \boldsymbol{P}, \mathbf{Q}$ ); overlapping expression domains appear in yellow. $\boldsymbol{N}^{\prime \prime}$ and $\mathbf{O}^{\prime \prime}$ are superimposed dark-field images after $D k k 3$ ISH (green pseudocolor in $\boldsymbol{N}, \mathbf{O}$ ) and the corresponding bright-field views after TH IHC (VECTOR Red staining in $\boldsymbol{N}^{\prime}, \mathbf{O}^{\prime}$ ). Broken white lines in $\boldsymbol{B}-\boldsymbol{D}^{\prime}, \boldsymbol{F}-\boldsymbol{H}^{\prime}, \boldsymbol{J}, \boldsymbol{L}$ outline the neuroepithelium and in $\boldsymbol{J}$ delimit the FP and the VZ/SVZ from the MZ. Broken black lines in $\boldsymbol{E}$ delimit the FP and BP. Red arrows in $\boldsymbol{K}^{\prime}$ point to the weak Dkk3 ${ }^{+}$domain in the E15.5 rostrolateral VM, and white arrows in $\boldsymbol{N}^{\prime \prime}$ point to $\mathrm{TH}^{+}$cells that coexpress Dkk3. Inset in $\boldsymbol{N}^{\prime \prime}$ is a higher magnification of the framed cell. Cb, Cerebellum; CLi, caudal linear nucleus; $C \mathrm{CX}$ cortex; Di, diencephalon; DR, dorsal raphe nucleus; IF, interfascicular nucleus; Mes, mesencephalon; Met, metencephalon; Ob, olfactory bulb; PN, paranigral nucleus; RLi, rostral linear nucleus; RrF, retrorubral field; SNcd, Substantia nigra pars compacta dorsalis; T, tectum; Tg, tegmentum; Tel, telencephalon; III, third ventricle. 

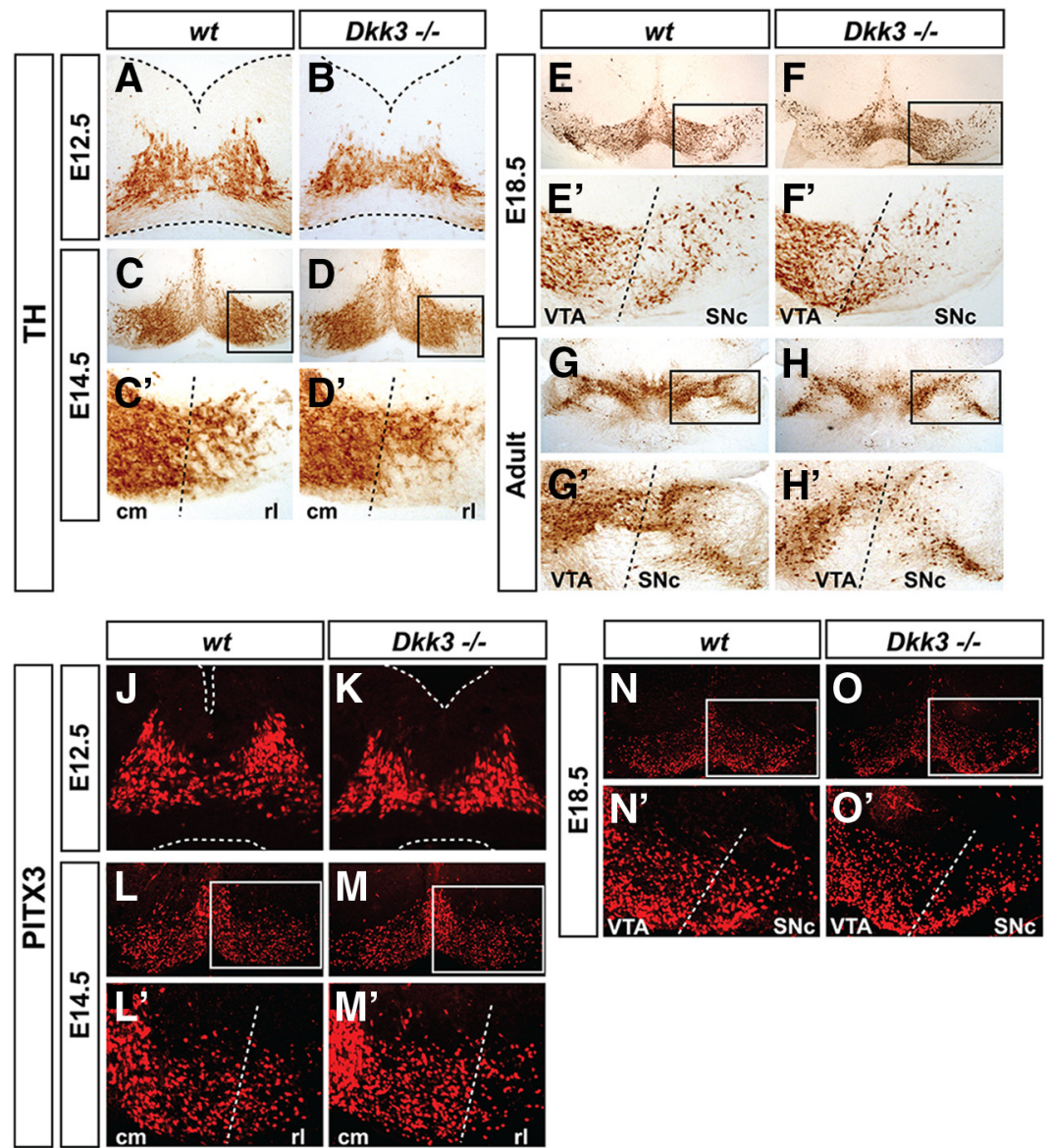
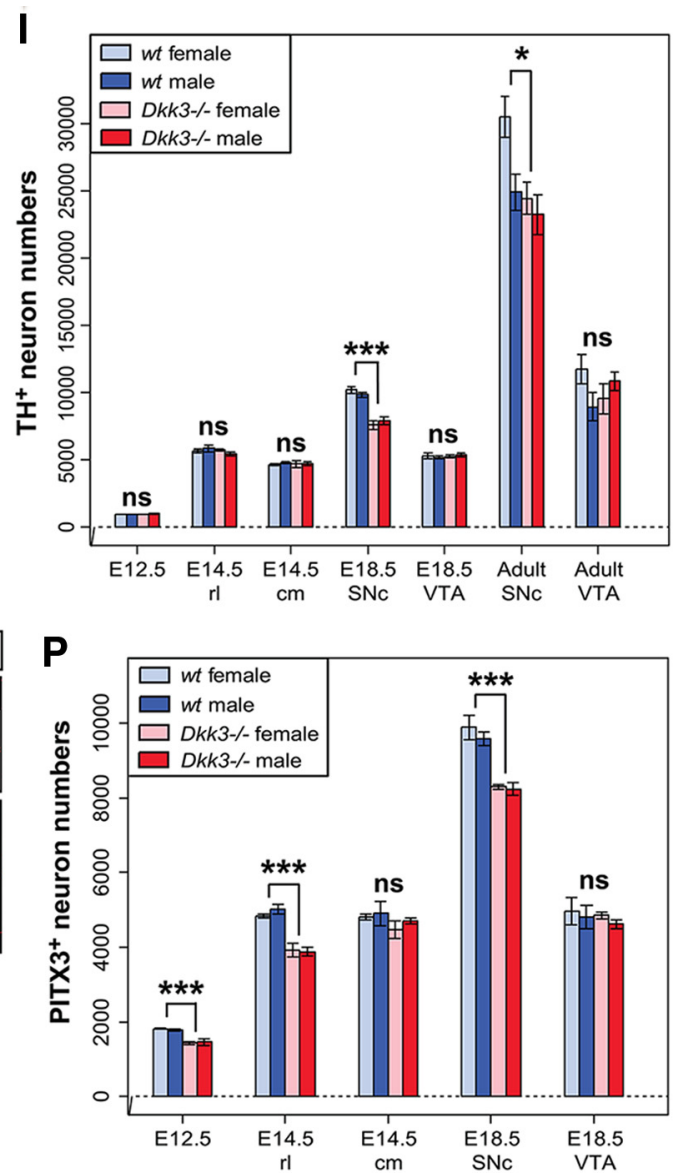

Figure 2. Midgestational PITX $3^{+}$cell loss and late gestational $\mathrm{TH}^{+}$cell reduction in the $D k k 3^{-/-}$midbrain. $\left(\boldsymbol{A}-\boldsymbol{H}^{\prime}, \mathbf{J}-\mathbf{O}^{\prime}\right)$ Representative close-up views of the VM on coronal $\left(\boldsymbol{A}-\boldsymbol{F}^{\prime}, \mathbf{J}-\mathbf{O}^{\prime}\right.$; dorsal top) and horizontal ( $\mathbf{G}-\boldsymbol{H}^{\prime} ;$ rostral top) sections from WT $(\boldsymbol{A}, \boldsymbol{C}, \boldsymbol{E}, \mathbf{G}, \boldsymbol{J}, \boldsymbol{L}, \boldsymbol{N})$ and $D k 3^{-/-}(\boldsymbol{B}, \boldsymbol{D}, \boldsymbol{F}, \boldsymbol{H}, \boldsymbol{K}, \boldsymbol{M}, \mathbf{0})$ embryos at E12.5 $(\boldsymbol{A}, \boldsymbol{B}, \boldsymbol{J}, \boldsymbol{K}), \mathrm{E} 14.5\left(\boldsymbol{C}-\boldsymbol{D}^{\prime}, \mathbf{L}-\boldsymbol{M}^{\prime}\right)$ and E18.5 $\left(\boldsymbol{E}-\boldsymbol{F}^{\prime}, \boldsymbol{N}-\mathbf{O}^{\prime}\right)$ or adult brains $\left(\mathbf{G}-\boldsymbol{H}^{\prime}\right)$, immunostained for TH $\left(\boldsymbol{A}-\boldsymbol{H}^{\prime}\right)$ or PITX3 $\left(\boldsymbol{J}-\boldsymbol{O}^{\prime}\right) . \boldsymbol{C}^{\prime}, \boldsymbol{D}^{\prime}, \boldsymbol{E}^{\prime}, \boldsymbol{F}^{\prime}, \boldsymbol{G}^{\prime}, \boldsymbol{H}^{\prime}, \boldsymbol{L}^{\prime}, \boldsymbol{M}^{\prime}, \boldsymbol{N}^{\prime}$, and $\boldsymbol{O}^{\prime}$ are higher magnifications of the boxed areas in $\boldsymbol{C}, \boldsymbol{D}, \boldsymbol{E}, \boldsymbol{F}, \mathbf{G}, \boldsymbol{H}, \boldsymbol{L}, \boldsymbol{M}, \boldsymbol{N}$, and $\mathbf{O}$, respectively. Broken black or white lines in $\boldsymbol{A}, \boldsymbol{B}$ and $\boldsymbol{J}, \boldsymbol{K}$ outline the neuroepithelium and in $\boldsymbol{C}^{\prime}, \boldsymbol{D}^{\prime}, \boldsymbol{E}^{\prime}, \boldsymbol{F}^{\prime}, \boldsymbol{G}^{\prime}, \boldsymbol{H}^{\prime}, \boldsymbol{L}^{\prime}, \boldsymbol{M}^{\prime}, \boldsymbol{N}^{\prime}$, and $\boldsymbol{O}^{\prime}$ delimit the rostrolateral (rl) or $\mathbf{S N}$ c domain from the caudomedial $(\mathrm{cm})$ or VTA domain, as indicated. $I, P$, Unbiased stereological quantification of $\mathrm{TH}^{+}(\boldsymbol{I})$ or PITX3 ${ }^{+}(\boldsymbol{P})$ cells in female or male WT and $D k k 3^{-1-}$ embryos and adult brains. ${ }^{*} p<0.05$; ${ }^{* * *} p<0.001$; $\mathrm{ns}$, not significant in the Welsh $t$ test for unequal variances.

for proper patterning of the midbrain/hindbrain region and neurogenesis in this region, such as $D k k 1 / 2, F g f 8, E n 1, S h h, W n t 1$, Ngn1, Ngn2, and Lmx1b (Wurst and Bally-Cuif, 2001; Hegarty et al., 2013), was unaffected in the $D k k 3^{-1-}$ embryos (data not shown), and we thus examined whether the generation of mdDA neurons was altered in the absence of $D k k 3$. Because $D k k 3^{-/-}$ mice exhibit a sex-related behavioral phenotype (del BarcoBarrantes et al., 2006), we also determined the sex of the corresponding embryos. The total number of $\mathrm{TH}^{+}$neurons in the $D k k 3^{-1-}$ VM was comparable with the WT VM at E12.5 and E14.5, but a significant and sex-independent reduction was detected in the rostrolateral (PBP and dorsomedial SNc) domain of the $D k k 3^{-1-}$ embryos at E18.5 (20-25\% less $\mathrm{TH}^{+}$neurons) and in adult $D k k 3^{-1-}$ mice (7-20\% less $\mathrm{TH}^{+}$neurons) (Fig. $2 A-I$ ). Notably, the total number of PITX $3^{+}$cells was already reduced significantly and sex independently by $18-21 \%$ in the $D k k 3^{-1-}$ embryos at E12.5 and by $14-23 \%$ in the rostrolateral (PBP and dorsomedial SNc) region of the mutant VM at E14.5 and E18.5 (Fig. 2J-P). In contrast to the rostrolateral (PBP and dorsomedial $\mathrm{SNc}$ ) domain, the caudomedial (VTA) region was not affected in the $D k k 3^{-1-}$ embryos and mice (Fig. $2 A-P$ ). To assess this aberrant differentiation and loss of an mdDA neuron subset in more detail, we first determined the numbers of proliferating $\mathrm{LMX} \mathrm{A}^{+} / \mathrm{EdU}^{+}$mdDA progenitors, postmitotic $\mathrm{LMX1A}^{+}$/
$\mathrm{EdU}^{-}$mdDA precursors, and mitotic $\mathrm{pH} 3^{+} \mathrm{VM}$ neural progenitors in the $D k k 3^{-/-}$VM. Because these numbers were not altered in the mutant VM (Fig. $3 A-C$ and data not shown), we next determined the numbers of TH or PITX3 single- and doublepositive cells at different developmental stages in the $D k k 3^{-/-}$ and WT embryos. $\mathrm{TH}^{+} / \mathrm{PITX}^{-}$single-positive cells were increased significantly by $\sim 2$-fold (at E12.5) to 2.8 -fold (at E14.5) at the expense of $\mathrm{TH}^{+} / \mathrm{PITX}^{+}$double-positive cells, which were decreased by $22 \%$ (at E12.5) to $26 \%$ (at E14.5) in the mutant VM (Fig. 3D- $G^{\prime}, J, K$ ). Although the numbers of $\mathrm{TH}^{-}$/ $\mathrm{PITX}^{+}$single-positive cells were not altered at E12.5, they were significantly decreased by $39 \%$ in the rostrolateral region of the $D k k 3^{-1-}$ VM at E14.5 (Fig. 3D-G' $J, K$ ). These results might account for the initial observation of decreased PITX $3^{+}$but normal $\mathrm{TH}^{+}$cell numbers in the mutant VM at E12.5 and E14.5 (Fig. 2). However, the total number of $\mathrm{TH}^{+}$cells was reduced in the mutant rostrolateral (PBP and dorsomedial SNc) domain at E18.5 (Fig. 2) and consistent with this finding, $\mathrm{TH}^{+} / \mathrm{PITX}^{-}$, $\mathrm{TH}^{-} / \mathrm{PITX}^{+}{ }^{+}$, and $\mathrm{TH}^{+} / \mathrm{PITX}^{+}$single- and double-positive cells were decreased by 38,50 , and $21 \%$, respectively, in the rostrolateral (PBP and dorsomedial SNc) mdDA domain of the E18.5 Dkk3 ${ }^{-1-}$ embryos (Fig. $3 H-I^{\prime}, L$ ). The lack of these cells was most notable in the mutant PBP and dorsal tier of the SNc at this stage (Fig. $3 H-I^{\prime}$ ). Because the loss of an mdDA neuron 


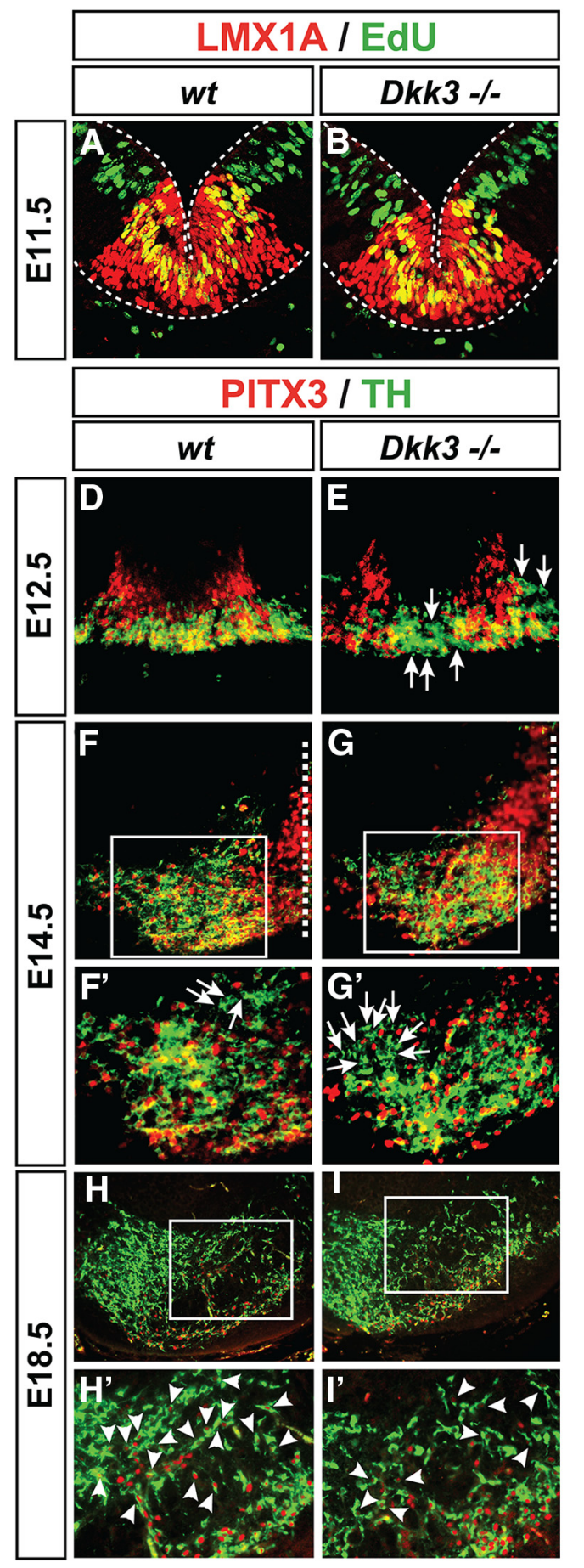

C
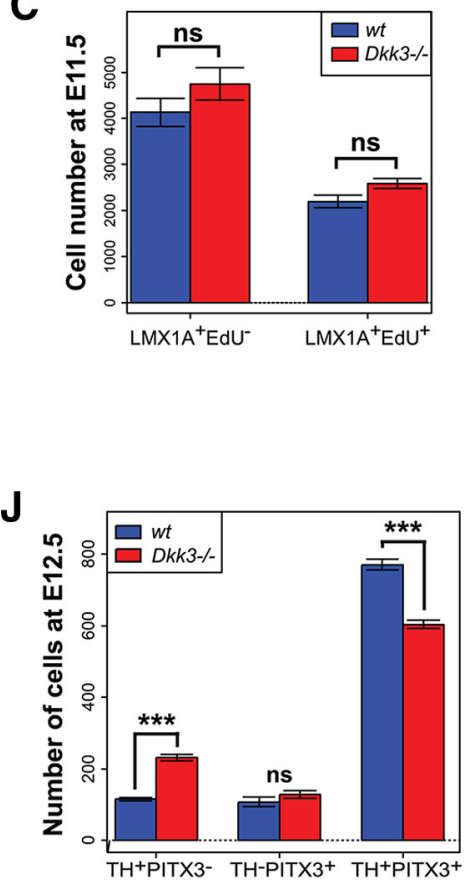

$\mathbf{K}$

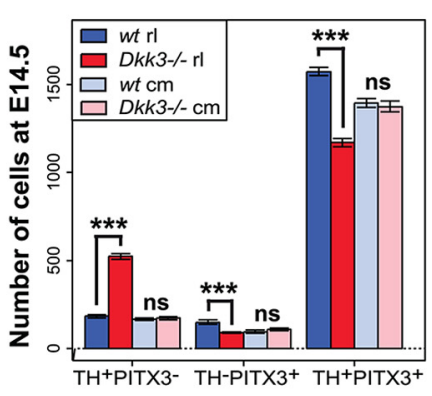

$\mathbf{L}$

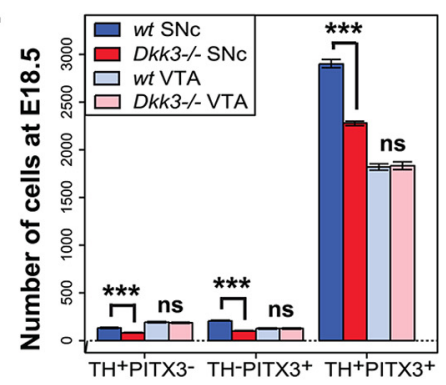

Figure 3. $D k k 3$ is required for the correct differentiation of rostrolateral $m d D A$ neurons in vivo. $A, B, D-I$, Representative confocal close-up views of the VM on coronal sections (dorsal top) from WT $(\boldsymbol{A}, \boldsymbol{D}, \boldsymbol{F}, \boldsymbol{H})$ and $D k 3^{-/-}(\boldsymbol{B}, \boldsymbol{E}, \boldsymbol{G}, \boldsymbol{I})$ embryos at E11.5 $(\boldsymbol{A}, \boldsymbol{B})$, E12.5 $(\boldsymbol{D}, \boldsymbol{E}), \mathrm{E} 14.5(\boldsymbol{F}, \boldsymbol{G})$, and E18.5 $(\boldsymbol{H}, \boldsymbol{I})$, immunostained for LMX1A (red) and EdU (green) $(\boldsymbol{A}, \boldsymbol{B})$, or PITX3 (red) and TH (green) $(\boldsymbol{D}-\boldsymbol{I})$. Broken white lines in $\boldsymbol{A}$ and $\boldsymbol{B}$ outline the neuroepithelium and in $\boldsymbol{F}$ and $\boldsymbol{G}$ indicate the midline. $\boldsymbol{F}^{\prime}, \boldsymbol{G}^{\prime}, \boldsymbol{H}^{\prime}$, and $\boldsymbol{I}^{\prime}$ are higher magnifications of the boxed areas in $\boldsymbol{F}, \boldsymbol{G}, \boldsymbol{H}$, and $\boldsymbol{I}$, respectively. White arrows in $\boldsymbol{E}, \boldsymbol{F}^{\prime}$, and $\boldsymbol{G}^{\prime}$ point to TH ${ }^{+}$/PITX3 single-positive cells; white arrowheads in $\boldsymbol{H}^{\prime}$ and $\boldsymbol{I}^{\prime}$ point to $\mathrm{TH}^{+} / \mathrm{PITX} 3^{+}$double-positive cells. C, Quantification of LMX1A ${ }^{+} /$ $\mathrm{EdU}^{-}$and $\mathrm{LMX1A^{+ }} / \mathrm{EdU}^{+}$cells in the WT and $D \mathrm{kk3} 3^{-/-}$VM at E11.5 ( $n=3$ embryos/genotype). J-L, Quantification of $\mathrm{TH}^{+} /$ PITX3 ${ }^{-}{ }^{-}$TH $^{-} /$PITX3 ${ }^{+}$, and TH ${ }^{+} /$PITX3 ${ }^{+}$cells in WT and Dkk3 ${ }^{-/-}$embryos at E12.5 (J), E14.5 (K), and E18.5 (L) $(n \geq 6$ embryos/ genotype/stage). ${ }^{* *} p<0.001$; ns, not significant in the paired $t$ test. $\mathrm{cm}$, Caudomedial mdDA domain; $\mathrm{rl}$, rostrolateral mdDA domain.

subset in the $D \mathrm{kk3}^{-/-}$mice might also be attributable to a reduced survival of the corresponding cells, we determined the numbers of $\mathrm{TH}^{+} / \mathrm{cCASP}^{+}$apoptotic $\mathrm{mdDA}$ neurons and $\mathrm{TH}^{-} /$ cCASP $^{+}$VM cells in the WT and Dkk3 mutant VM at E18.5.
These numbers were not altered in the $D k k 3^{-1-}$ VM (data not shown). Thus, our data indicated that a $\mathrm{TH}^{+} / \mathrm{PITX} 3$ mdDA precursor subpopulation failed to differentiate correctly into $\mathrm{TH}^{+} / \mathrm{PITX}^{+}$ mdDA neurons in the absence of $D k k 3$, resulting in an initial accumulation of $\mathrm{TH}^{+} / \mathrm{PITX}^{-}$single-positive cells at the expense of $\mathrm{TH}^{+} / \mathrm{PITX}^{+}$double-positive neurons in the mutant VM and the later loss of these $\mathrm{TH}^{+}$rostrolateral (PBP and dorsomedial SNc) mdDA neurons. However, the proliferation and specification of the corresponding mdDA progenitors/ precursors were not affected by the lack of $D k k 3$ in the murine VM.

DKK3 promotes the differentiation and survival of an mdDA neuron subset in vitro

Our previous results indicated that the differentiation of an mdDA neuronal subset was compromised in the absence of $D k k 3$. Therefore, we investigated whether the exogenous application of DKK3 protein might rescue this phenotype in primary VM cells isolated from E11.5 $D k k 3^{-1-}$ embryos. After 4 d (i.e., 6 DIV; see Materials and Methods) of BSA (vehicle control) or DKK3 treatment, a significant and approximately twofold increase of $\mathrm{TH}^{+} / \mathrm{PITX} 3^{-}$single-positive cells and an $\sim 56 \%$ decrease of $\mathrm{TH}^{+} / \mathrm{PITX}^{+}$ double-positive cells were detected in the $D k k 3^{-1-}$ compared with the WT primary VM cultures (Fig. 4E), thus reflecting similar changes in the mutant VM at E12.5 (Fig. 3J). However, seven days of DKK3 treatment (i.e., after 9 DIV) led to a significant and almost twofold increase (relative to the BSA-treated cells) of $\mathrm{TH}^{+} /$ PITX $^{+}$double-positive cells in the WT cultures, whereas $\mathrm{TH}^{+} / \mathrm{PITX}^{-}$or $\mathrm{TH}^{-}$/ PITX $^{+}$single-positive cell numbers were not altered in these cultures (Fig. $4 A, B, E$ ). The DKK3 treatment also rescued the numbers of TH/PITX3 single- and double-positive cells in the $D k k 3^{-/-}$ cultures to approximately the same numbers as in control (BSA)-treated WT cultures after 9 DIV (Fig. 4A, C-E). At this time point (9 DIV), BSA treatment of the $D k k 3^{-\prime-}$ cultures resulted in a significant reduction of TH/PITX3 single-positive (by 50-56\%) and double-positive (by $74 \%$ ) cells (Fig. $4 A, C, E)$, thus reflecting similar changes in the mutant VM at E18.5 (Fig. 3L).

These results indicated that exogenous DKK3 protein promoted the differentiation of an $\mathrm{mdDA}$ precursor subset into $\mathrm{TH}^{+} / \mathrm{PITX}^{+}{ }^{+}$mdDA neurons under normal (WT) conditions and rescued the loss of TH/PITX3 single- and doublepositive cells in the $D k k 3^{-/-}$mutant cultures. 

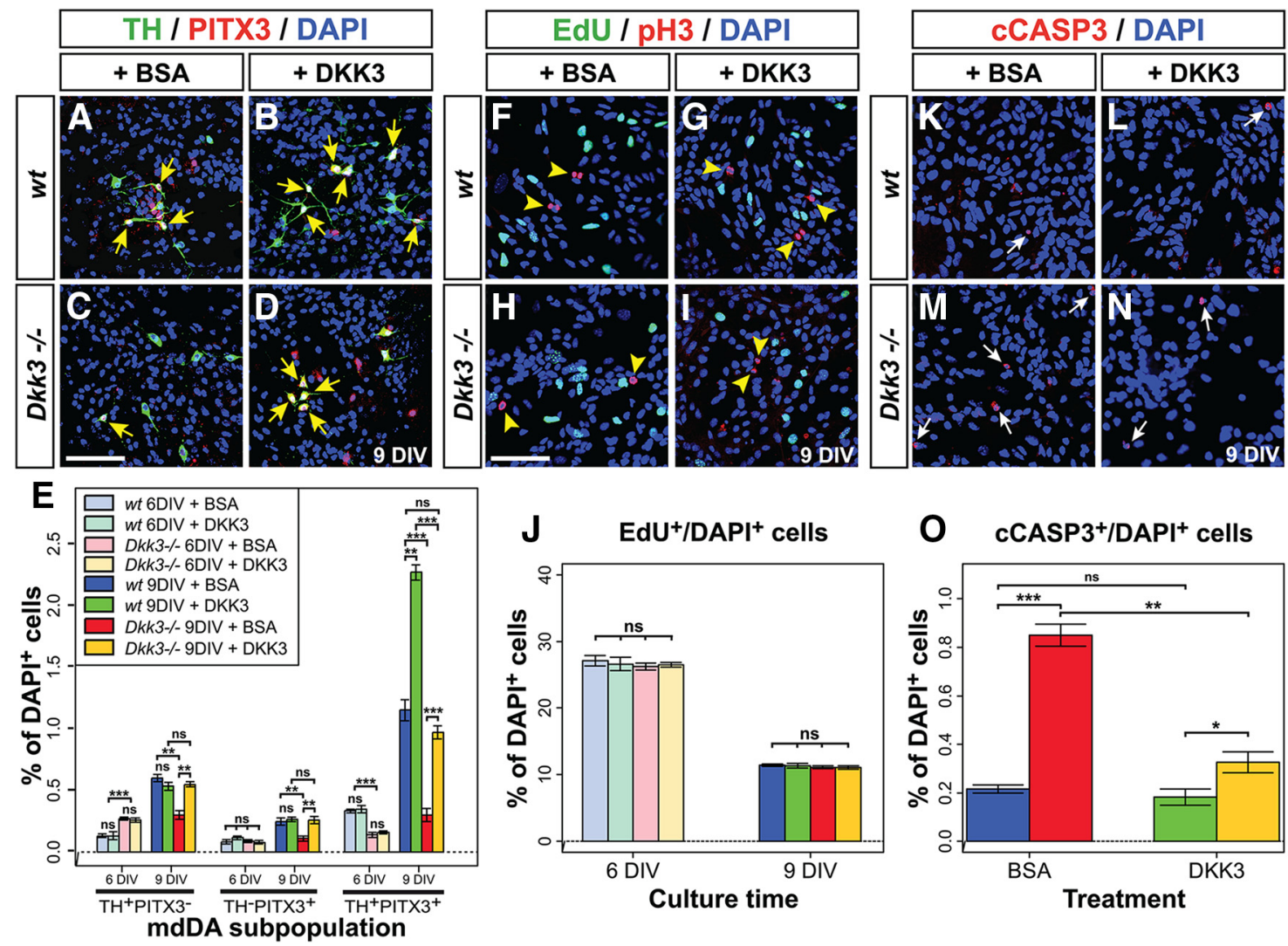

Figure 4. DKK3 promotes the differentiation and survival of an mdDA neuron subset in vitro. $\boldsymbol{A}-\boldsymbol{D}, \boldsymbol{F}-\boldsymbol{I}, \boldsymbol{K}-\boldsymbol{N}$, Representative confocal overviews of primary VM cells isolated from E11.5 WT (A, $\boldsymbol{B}, \boldsymbol{F}, \boldsymbol{G}, \boldsymbol{K}, \boldsymbol{L})$ and $D k \mathbf{k}^{-/-}(\boldsymbol{C}, \boldsymbol{D}, \boldsymbol{H}, \boldsymbol{I}, \boldsymbol{M}, \boldsymbol{N})$ embryos and treated for $7 \mathrm{~d}(9 \mathrm{DIV})$ with BSA (control; $\left.\boldsymbol{A}, \boldsymbol{C}, \boldsymbol{F}, \boldsymbol{H}, \boldsymbol{K}, \boldsymbol{M}\right)$ or DKK3 $(\boldsymbol{B}, \boldsymbol{D}, \boldsymbol{G}, \boldsymbol{I}, \boldsymbol{L}, \boldsymbol{N})$ protein. Cells were immunostained for TH (green) and PITX3 (red) $(\boldsymbol{A}-\boldsymbol{D})$, EdU (green) and pH3 (red) $(\boldsymbol{F}-\boldsymbol{I})$, or cCASP3 (red) $(\boldsymbol{K}-\boldsymbol{N})$ and counterstained with DAPI (blue). Yellow arrows in $\boldsymbol{A}-\boldsymbol{D}$ point to $\mathrm{TH}^{+} / \mathrm{PITX}^{+}{ }^{+} \mathrm{mdDA}$ neurons, yellow arrowheads in $\boldsymbol{F}-\boldsymbol{I}$ point to $\mathrm{pH} 3^{+}$mitotic cells, and white arrows in $\boldsymbol{K}-\boldsymbol{N}$ point to $\mathrm{CCASP} 3^{+}$apoptotic cells. $\boldsymbol{E}, \boldsymbol{J}, \mathbf{O}$, Quantification of $\mathrm{TH}^{+} / \mathrm{PIXX}^{-}, \mathrm{TH}^{-} / \mathrm{PITX}^{+}$, and TH $^{+} / \mathrm{PITX} 3^{+}(\boldsymbol{E}), \mathrm{EdU}^{+}(\boldsymbol{J})$, and

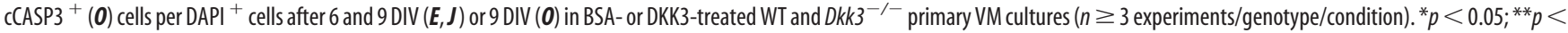
$0.01 ; * * * 0.001 ; \mathrm{ns}$, not significant in the $t$ test. Color coding of bars shown in $\boldsymbol{J}$ and $\boldsymbol{O}$ as in the legend for $\boldsymbol{E}$. Scale bars: $\boldsymbol{C}, \boldsymbol{H}, 50 \mu \mathrm{m}$.

The treatment of WT and $D k k 3^{-/-}$primary VM cultures with DKK3 protein did not change the numbers of proliferating $\mathrm{EdU}^{+}$(S-phase) and $\mathrm{pH}^{+}{ }^{+}$(M-phase) cells after $4 \mathrm{~d}(6$ DIV) or $7 \mathrm{~d}$ (9 DIV; Fig. $4 \mathrm{~F}-J$ ), indicating that DKK3 did not alter the proliferation of VM progenitors in vitro. However, the significant approximately fourfold increase of apoptotic $\left(\right.$ cCASP $\left.^{+}\right)$cells in the BSA-treated $D k k 3^{-/-}$cultures after 9 DIV was reduced by DKK3 treatment of these cultures to approximately one-third ( $\sim 38 \%$ ) (Fig. $4 K-O)$. Nevertheless, the numbers of apoptotic cells still remained significantly increased $(\sim 1.8$-fold $)$ in the mutant cultures relative to the DKK3-treated WT cultures (Fig. $4 K-O$ ). This suggested that exogenous DKK3 protein might promote to a certain extent the survival of Dkk3-deficient VM cells in vitro.

\section{DKK3 regulates the expression of LMX1A in mdDA}

\section{precursors and neurons in vivo and in vitro}

Our data so far indicated that DKK3 was required for the sustained expression of PITX3 in a developing mdDA neuronal subset. $D k k 3$ transcription initiates in the mouse VM at approximately the same time (E11.5) when Pitx3 starts to be expressed in postmitotic mdDA precursors and neurons (Fig. 1; Smidt and Burbach (2007)), and the two expression domains partly overlap in the developing mouse VM at this early developmental stage (Fig. $1 J$ ). However, previous data suggested that Pitx 3 is an indirect target gene of WNT1/ $\beta$-catenin signaling in the embryonic mouse VM, which is bound and activated by the direct WNT1/ $\beta$-catenin target and HD TF LMX1A (Chung et al., 2009). The numbers of $\mathrm{TH}^{-} / \mathrm{LMX} 1 \mathrm{~A}^{+}$single- and $\mathrm{TH}^{+} / \mathrm{LMX1A}^{+}$doublepositive cells were indeed decreased significantly by 40 and $12.5 \%$, respectively, in the rostrolateral but not caudomedial region of the $D k k 3^{-1-} \mathrm{VM}$ at E14.5 (Fig. $5 A-C$ ). In contrast, the numbers of $\mathrm{TH}^{+} / \mathrm{LMX} \mathrm{A}^{-}$single-positive cells were increased by $\sim 2.6$-fold in the rostrolateral mdDA domain of the mutants at this stage (Fig. $5 A-C$ ). These changes corresponded well with a similar decrease of $\mathrm{TH}^{-} / \mathrm{PITX}^{+}$(by 39\%) and increase of $\mathrm{TH}^{+} /$ PITX3 ${ }^{-}$(by $\sim 2.8$-fold) single-positive cells in the mutant VM at this stage (Fig. $3 K$ ). Conversely, DKK3 treatment of primary VM cells for $7 \mathrm{~d}$ (9 DIV) increased the transcription of Lmx1a by $\sim 1.5$-fold in the WT cultures and rescued the decreased expression of Lmx1a ( $\sim 33 \%$ reduction) in control (BSA)treated $D \mathrm{kk}^{-1-}$ cultures to levels similar to those of their BSA-treated WT counterparts (Fig. 5D). LMX1B is another LMX1 TF that also binds to the Pitx3 promoter and compensates partially for the loss of Lmx1a (Chung et al., 2009; Deng et al., 2011; Yan et al., 2011). In contrast to PITX3 and LMX1A, we did not detect any obvious changes of LMX1B expression in the $D k k 3^{-/}$VM at E12.5, except for an apparently slight reduction of $\mathrm{TH}^{+} / \mathrm{LMX} \mathrm{B}^{+}$double-positive cells at this stage (Fig. $5 E-J$ ). In line with this finding, the treatment of primary VM cells with DKK3 protein for $7 \mathrm{~d}$ ( 9 DIV) did not affect the endogenous expression of $L m \times 1 b$ in the mutant and WT cells (Fig. $5 K$ ). The selective failure of an mdDA precursor subset to differentiate into TH-, LMX1A-, and PITX3- 


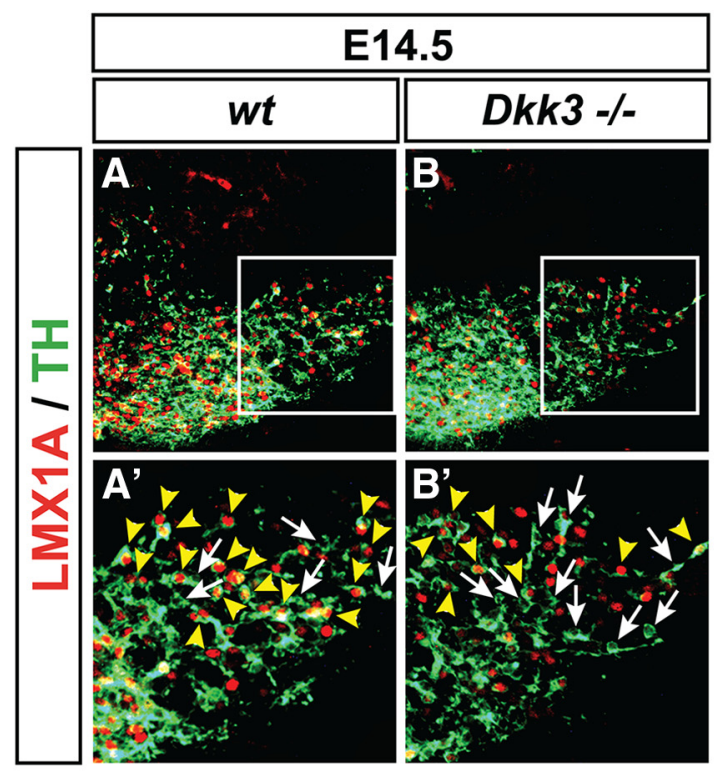

C

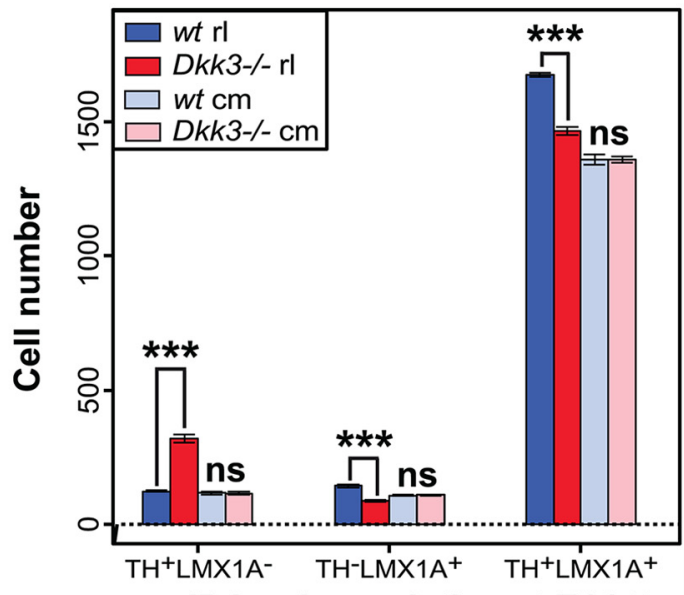

D mdDA subpopulation at E14.5
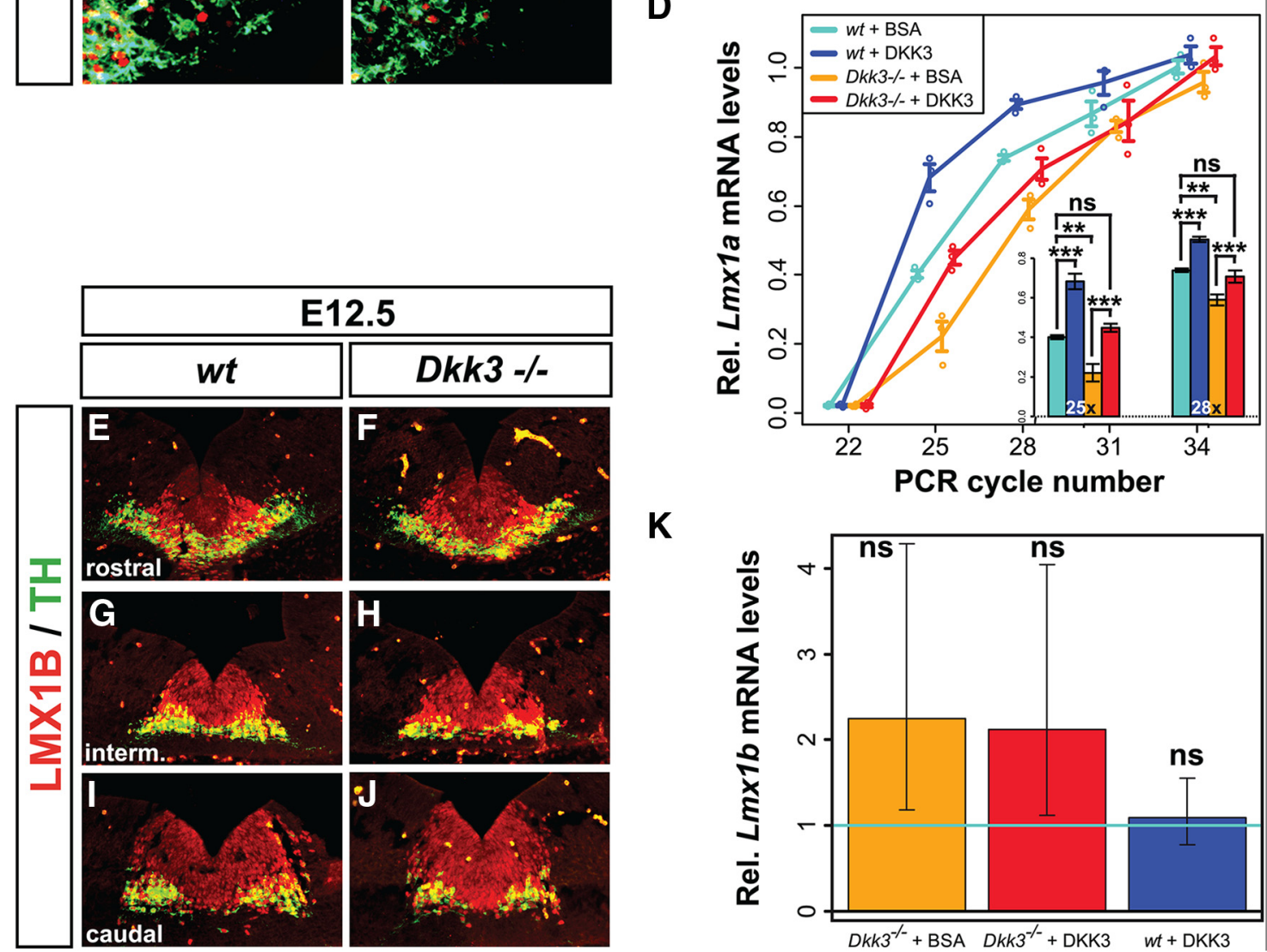

$\mathbf{K}$

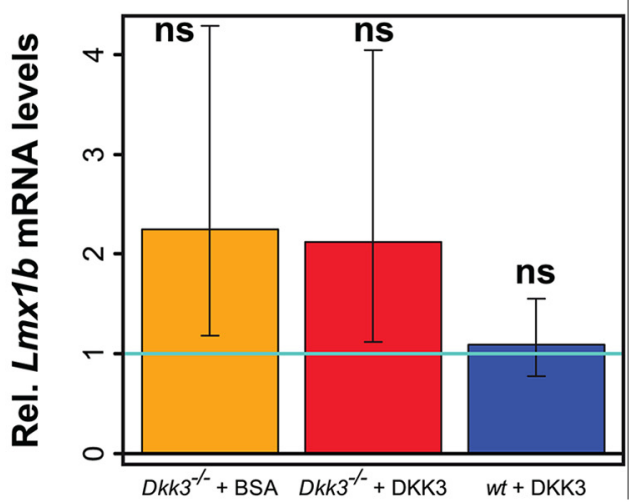

Figure 5. DKK3 regulates the expression of $L M X 1 A$ in $m \mathrm{mDA}$ precursors and neurons in vivo and in vitro. $A, B$, Representative close-up views of the VM on coronal sections (dorsal top) from WT ( $A$ ) and $D k k 3^{-/-}(\boldsymbol{B})$ embryos at E14.5, immunostained for LMX1A (red) and TH (green). $\boldsymbol{A}^{\prime}$ and $\boldsymbol{B}^{\prime}$ are higher magnifications of the boxed areas in $\boldsymbol{A}$ and $\boldsymbol{B}$, respectively. White arrows in $\boldsymbol{A}^{\prime}$ and $\boldsymbol{B}^{\prime}$ point

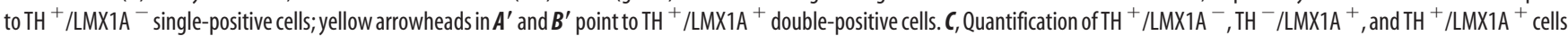

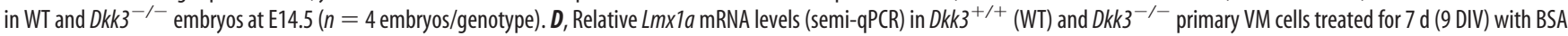
$(+B S A)$ or DKK3 ( + DKK3) protein ( $n=3$ experiments/genotype/treatment). $\boldsymbol{E}-\boldsymbol{J}$, Representative close-up views of the VM on coronal sections (dorsal top) from WT $(\boldsymbol{E}, \mathbf{G}, \boldsymbol{I})$ and $D k k 3^{-/-}(\boldsymbol{F}, \boldsymbol{H}$, $\boldsymbol{J}$ ) embryos at E12.5, immunostained for LMX1B (red) and TH (green). Sections are from anterior $(\boldsymbol{E}, \boldsymbol{F})$, intermediate $(\boldsymbol{G}, \boldsymbol{H})$, and posterior $(\boldsymbol{I}, \boldsymbol{J})$ levels of the VM. $\boldsymbol{K}$, Relative $L m \times 1 b m R N A$ levels ( $\mathrm{gPCR})$ in WT and Dkk3 ${ }^{-/-}$primary VM cells treated for $7 \mathrm{~d}(9 \mathrm{DIV})$ with BSA or DKK3 protein [fold-change relative to the untreated WT control (wt + BSA) set as 1, light blue line; $n=3$ experiments/genotype/treatment]. Error bars in $\boldsymbol{K}$ represent $95 \%$ confidence intervals; ${ }^{* *} p<0.01 ;{ }^{* * *} p<0.001$; ns, not significant in the unpaired $t$ test (genotypes)/paired $t$ test (treatments). $\mathrm{cm}$, Caudomedial mdDA domain; $\mathrm{rl}$, rostrolateral mdDA domain.

expressing rostrolateral (PBP and dorsomedial SNc) mdDA neurons, and the later loss of these neurons, was therefore most likely attributable to the failure to sequentially activate and/or maintain the transcription of Lmxla and Pitx3 in these cells in the absence of $D k k 3$.
Combined DKK3/WNT1 treatment generates the highest proportion of $\mathrm{TH}^{+} / \mathrm{PITX}^{+}{ }^{+}$mdDA neurons from differentiating murine PSCs

The previous results prompted us to investigate whether the treatment of PSCs (mouse ESCs and iPSCs) with DKK3 protein 
might enhance their differentiation into $\mathrm{TH}^{+}$and PITX3 ${ }^{+}$ mdDA neurons. We tested the function of DKK3 in the absence and presence of WNT1, because the WNT1 ligand might be necessary for the action of DKK3 in these cultures and/or because both soluble factors might act synergistically during PSC differentiation. The high variability of differentiation outcomes using the published embryoid body-based "five-stage" protocol (Lee et al., 2000) for the differentiation of mouse ESCs into mdDA neurons (data not shown) motivated us to develop an adherent monolayer differentiation protocol that was adapted from established procedures for the neural and mdDA differentiation of mouse and human PSCs (Chambers et al., 2009; Jaeger et al., 2011; Kriks et al., 2011). For this purpose, we also generated a transgene-free ( $\mathrm{tf}$ ) and "mdDA-reporter" iPSC line (Pitx $3^{\text {GFP/+ }}$ iPSC $^{\mathrm{tf}} \mathrm{s}$ ) from Pitx $3^{G F P /+}$ MEFs (Pertek et al., 2014). The treatment of differentiating Pitx $3^{G F P /+}$ iPSC $^{\text {tf }}$ S with recombinant DKK3 and WNT1 proteins consistently led to the highest number of $\mathrm{TH}^{+} / \mathrm{PITX}^{+}$double-positive cell clusters compared with all other conditions and promoted the generation of $\mathrm{TH}^{+}$/ $\mathrm{PITX}^{+}$double-positive cells at the expense of $\mathrm{TH}^{+} / \mathrm{PITX}^{-}$ single-positive cells in these clusters, reaching up to $\sim 77 \% \mathrm{TH}^{+} /$ $\mathrm{PITX}^{+}$double-positive cells among the generated $\mathrm{TH}^{+}$neurons (Fig. 6A-J). This effect was reproduced independently with another murine PSC line [NesE-eGFP mouse ESCs (Friling et al., 2009); data not shown] and corresponded to similar changes observed after DKK3 treatment of primary VM cells (Fig. 4). Remarkably, the treatment of differentiating Pitx $3^{G F P /+}$ iPSC $^{\text {tf }}$ S with the potent GSK3b inhibitor and $\mathrm{WNT} / \beta$-catenin signaling activator CHIR99 (Kriks et al., 2011) reduced significantly the numbers of $\mathrm{TH}^{+} / \mathrm{PITX}^{+}$double-positive cell clusters and had no significant effect on double-positive cell densities in these clusters (Fig. $6 \mathrm{D}, \mathrm{H}, \mathrm{I}$ ). The $\mathrm{TH}^{+}$mdDA neurons generated after combined DKK3 + WNT1 treatment of differentiating Pitx $3^{\text {GFP/+ }}$ iPSC ${ }^{\mathrm{tf}}$ s also expressed other markers typical for these cells, such as the HD TF EN1 and NURR1 (Fig. $6 K, L$ ). The densities of $\mathrm{TH}^{+} / \mathrm{NR} 4 \mathrm{~A} 2^{+}$double-positive cells showed a similar tendency to be increased at the expense of $\mathrm{TH}^{+} / \mathrm{NR}_{4} \mathrm{~A} 2^{-}$singlepositive cells after combined DKK3 + WNT1 treatment of differentiating Pitx $3^{G F P /+}$ iPSC ${ }^{\text {tf }} \mathrm{s}$, and the proportion of $\mathrm{TH}^{+} /$ NR4A2 ${ }^{+}$double-positive cells among all $\mathrm{TH}^{+}$neurons was also significantly increased to $\sim 87 \%$ under these conditions (Fig. $6 M, N)$. Because the combined DKK3 + WNT1 treatment generated the highest proportions of $\mathrm{PITX}^{+} / \mathrm{TH}^{+}$and $\mathrm{NR} 4 \mathrm{~A} 2^{+} /$ $\mathrm{TH}^{+}$double-positive cells compared with all other conditions tested (Fig. $6 \mathrm{~J}, \mathrm{~N}$ ), we concluded that DKK3 together with WNT1 indeed promoted the differentiation of murine PSCs into $\mathrm{TH}^{+}$, $\mathrm{PITX}^{+}$, and NR4A2 ${ }^{+}$mdDA neurons.

\section{Global gene expression changes in DKK3/WNT1-treated versus untreated iPSC-derived Pitx $3^{\mathrm{GFP} /+}$ mdDA neurons} To assess the global effects of the combined DKK3 + WNT1 treatment on the transcriptome of the iPSC-derived Pitx $3^{\text {GFP/+ }}$ mdDA neurons in relation to the untreated (only FGF8b-treated) and the endogenous (in vivo differentiated) E13.5/E14.5 Pitx $3^{G F P /+}$ mdDA neurons, we performed a microarray-based gene expression profiling of these cells. For this purpose, we took advantage of their endogenous expression of enhanced GFP (eGFP) under the control of the Pitx3 promoter and feasibility for direct FACS (Zhao et al., 2004; Pertek et al., 2014 and data not shown; Fig. 7A). Heat map comparison of five independent differentiation experiments showed that the expression of 460 probe sets corresponding to 422 distinct genes was consistently $(p<$ 0.05) upregulated or downregulated in the DKK3 + WNT1- treated compared with the untreated iPSC-derived Pitx $3^{G F P /+}$ mdDA neurons (Fig. 7B). GO term enrichment analyses of these differentially regulated genes revealed the overrepresentation of GO terms such as developmental/metabolic processes, cell differentiation, and cell migration (Fig. 7C). However, hierarchical clustering analysis showed that the primary Pit $x 3^{G F P /+} \mathrm{mdDA}$ neurons isolated from the E13.5 and E14.5 VM formed a distinct group from the iPSC-derived Pitx $3^{G F P /+}$ mdDA neurons (Fig. $6 D)$. A closer inspection of selected mdDA progenitor- and neuron-specific genes in these groups revealed that some genes expressed in PSCs and implicated in neural induction and/or mdDA neurogenesis [such as Tgfb3, Sox2, and Tgfb1, (Oshimori and Fuchs, 2012; Sarkar and Hochedlinger, 2013; Hegarty et al., 2014)] were upregulated, whereas the majority of genes transcribed in maturing mdDA neurons [including Th, Nr4a2, En1, Drd2, Lmx1a/b, Slc6a3, Pitx3, Calb1, and Kcnj6, (Smidt and Burbach, 2007; Hegarty et al., 2013)] were expressed at lower levels in the iPSC-derived compared with the primary Pit $x 3^{G F P /+}$ mdDA neurons (Fig. 7E). Notably, some midbrain FP and mdDA progenitor marker genes [such as Corin, Ascl1, and Foxp1 (Kele et al., 2006; Ono et al., 2007; Konstantoulas et al., 2010)] were expressed at similar levels in primary and iPSC-derived mdDA neurons (Fig. $7 E$ ). There was little or no variation in the transcript levels of these genes between the DKK3 + WNT1-treated and untreated iPSC-derived Pit $x 3^{G F P /+}$ mdDA neurons relative to their in vivo counterparts (Fig. $7 E$ ). Moreover, the global transcriptome profiling of the DKK3 + WNT1-treated versus untreated iPSC-derived Pit $x 3^{G F P /+}$ mdDA neurons did not reveal any significant $(p<0.05)$ changes between both treatments in the expression levels of selected genes associated with $\mathrm{WNT} / \beta$ catenin signaling and mdDA neuron development in vivo, except for Sox17, Sox10, Wnt4, Fzd2, and Sfrp4, which were significantly downregulated in the DKK3 + WNT1-treated cells (data not shown). These data showed that the DKK3 + WNT1 treatment had clear effects on the global gene expression profile of the in vitro-differentiated (iPSC-derived) mdDA neurons, but PSCspecific and especially mdDA-specific transcript levels in these cells appeared to be influenced by their derivation from reprogrammed MEFs (Roessler et al., 2014).

\section{$\mathrm{WNT} / \boldsymbol{\beta}$-catenin factor treatment promotes a rostrolateral (SNc) DA and suppresses a caudomedial (VTA) DA neuronal fate in differentiating PSCs in vitro}

The selective requirement of DKK3 for the correct differentiation of a rostrolateral (PBP and dorsomedial SNc) mdDA neuron subset in vivo suggested that $\mathrm{WNT} / \beta$-catenin factor treatment of differentiating PSCs might also promote the generation of this particular mdDA neuron subtype in vitro. Because of the lack of a specific and restricted marker for this mdDA neuronal subtype, we used CALB1 (also known as CalbindinD28K), a calciumbinding protein confined mostly to PITX3 ${ }^{-}$VTA and dorsomedial SNc DA neurons (Liang et al., 1996; Fu et al., 2012; Luk et al., 2013), and KCND3 (also known as Kv4.3), an A-type potassium channel subunit expressed in mature SNc DA neurons (Serôdio and Rudy, 1998; Liss et al., 2001) to discriminate at least between these two neuronal subsets among the in vitro-differentiated (iPSC-derived) mdDA neurons. The treatment of differentiating Pitx $3^{\text {GFP/+ }}$ iPSC $^{\text {tf }}$ s with CHIR99, DKK3, and/or WNT1 led to a significant decrease (by $\sim 51 \%$ ) of the proportion of $\mathrm{TH}^{+}$neurons coexpressing CALB1 (Fig. $8 A, B, F$ ) and a significant increase (by $\sim 39 \%$ ) of the proportion of $\mathrm{TH}^{+}$neurons coexpressing KCND3 (Fig. $8 A, C, G$ ). Although the majority of the $\mathrm{TH}^{+}{ }^{\mathrm{iPSC}}$ derived Pit $x 3^{G F P /+}$ mdDA neurons also expressed the DAT (also 


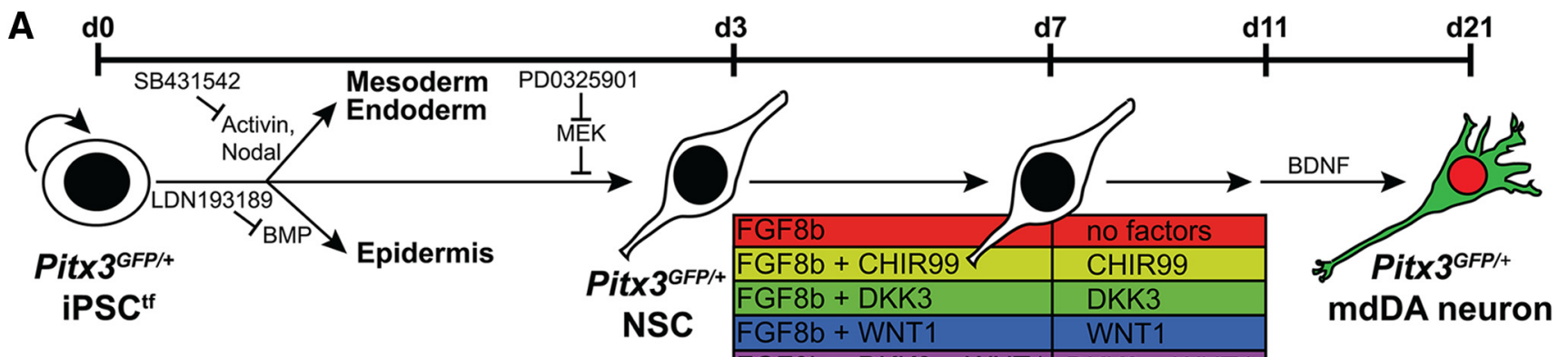

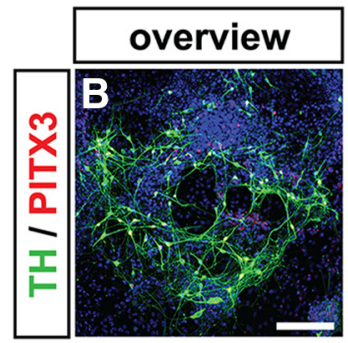

H

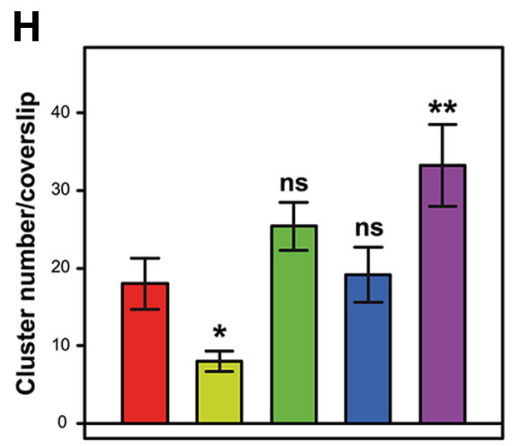

$\mathrm{TH}^{+} / \mathrm{PITX}^{+}$clusters
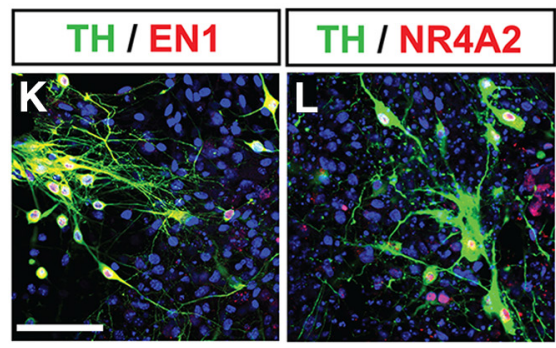
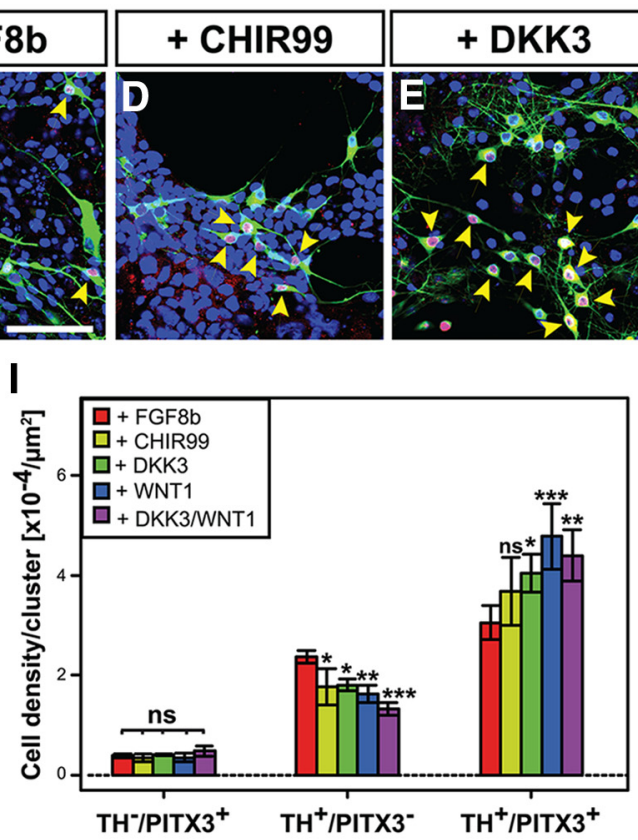

M

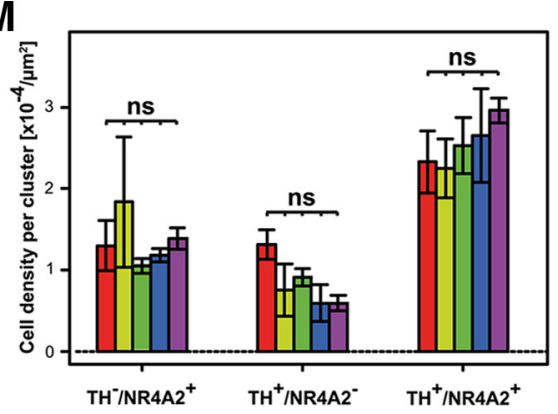

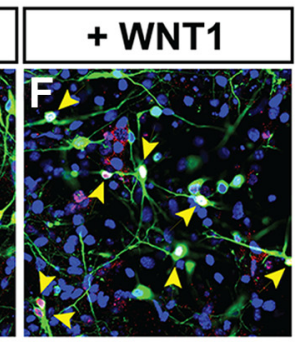

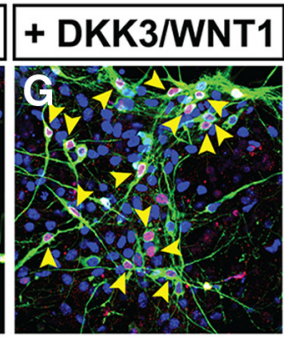

J

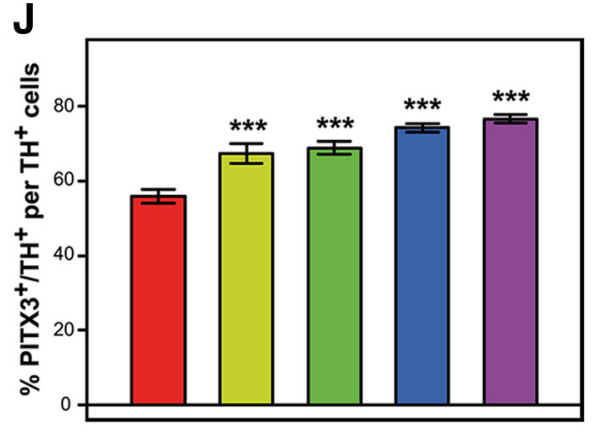

Treatment

N

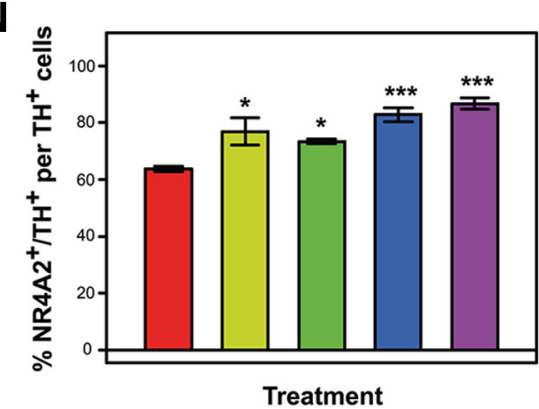

Figure 6. Combined DKK3/WNT1 treatment generates the highest proportion of $\mathrm{FH}^{+} / \mathrm{PITX} 3^{+}$and $\mathrm{TH}^{+} / \mathrm{NR}_{\mathrm{AA2}}{ }^{+} \mathrm{mdDA}$ neurons from differentiating murine iPSCS. $A$, Scheme of the monolayer protocol for the differentiation of Pitx $3^{\text {GFP/+ }}{ }^{\text {iPSC }}{ }^{\text {tf }}$ s into $\mathrm{mdDA}$ neurons. $\boldsymbol{B}-\mathbf{G}$, Representative confocal overview $(\boldsymbol{B})$ and close-up views $(\boldsymbol{C}-\boldsymbol{G})$ of TH ${ }^{+}(\mathrm{green})$ and PITX3 ${ }^{+}($red) cells (yellow arrowheads) after treatment of differentiating Pitx $3^{G F P /+}{ }^{\text {iPSC }}{ }^{\text {tf }}$ s with FGF8b alone $\left(\boldsymbol{C}\right.$ or together with CHIR99 (D), DKK3 (E), WNT1 (F), or DKK3 + WNT1 (B, G). H, I, Quantification of TH ${ }^{+} /$PITX3 ${ }^{+}$ double-positive cell clusters per coverslip $(\boldsymbol{H})$ and TH/PITX3 single- and double-positive cell densities within these clusters $(\boldsymbol{I})$ after treatment of differentiating Pitx ${ }^{G F P /+}{ }^{\text {PPSC }}{ }^{\mathrm{tf}} \boldsymbol{S}$ with different factor combinations ( $n=5$ experiments/condition).J, Quantification of the proportion of PITX ${ }^{+} / \mathrm{TH}^{+}$double-positive cells among all TH ${ }^{+}$cells in these cultures ( $n=3$ experiments/condition). $\boldsymbol{K}, \boldsymbol{L}$, Representative confocal close-up views of TH ${ }^{+}$(green)/EN1 ${ }^{+}$(red) $(\boldsymbol{K})$ and TH ${ }^{+}$(green)/NR4A2 ${ }^{+}$(red) $(\boldsymbol{L})$ cells after treatment of differentiating Pitx $3^{\text {GFP/+ }}{ }_{\text {iPSC }}{ }^{\mathrm{tf}}$ S with DKK3 + WNT1. $\boldsymbol{M}$, $\boldsymbol{N}$, Quantification of TH/NR4A2 single- and double-positive cell densities within clusters $(\boldsymbol{M})$ and the proportion of NR4A2 ${ }^{+} / \mathrm{TH}^{+}$double-positive cells among all TH ${ }^{+}$cells $(\boldsymbol{N})$ after treatment of differentiating Pitx ${ }^{G F P /+}{ }_{\text {iPSC }}^{\text {tf }}$ s with different factor combinations ( $n=3$ experiments/condition). Color coding of bars in $\boldsymbol{H}-\boldsymbol{J}, \boldsymbol{M}$, and $\boldsymbol{N}$ as indicated in the scheme in $\boldsymbol{A}$; statistical testing for significance in $\boldsymbol{H}-\boldsymbol{J}, \boldsymbol{M}$, and $\boldsymbol{N}$ was always done in relation to the untreated (only FGF8b-treated) cells. ${ }^{*} p<0.05 ;{ }^{* *} p<0.005 ;{ }^{* * *} p<0.001$; ns, not significant in one-way $(\boldsymbol{H}, \boldsymbol{J}, \boldsymbol{N})$ or two-way $(\boldsymbol{I}, \boldsymbol{M})$ ANOVA relative to the FGF8b-treated cells. Scale bars: $\boldsymbol{B}, 100 \mu \mathrm{m} ; \boldsymbol{C}, \boldsymbol{K}, 50 \mu \mathrm{m}$.

known as SLC6A3; Fig. 8D), only a subset of these cells coexpressed the G-protein-activated inwardly rectifying potassium channel GIRK2 (also known as KCNJ6; Fig. 8E), which is detected in SNc and VTA DA neurons (Fu et al., 2012; Reyes et al., 2012). Altogether, our data indicated that $\mathrm{WNT} / \beta$-catenin factor treatment of differentiating mouse PSCs indeed promoted, at least at the molecular level, a PITX $3^{+} / \mathrm{CALB}^{-} / \mathrm{KCND}^{+} / \mathrm{DAT}^{+}{ }$iden- tity (dorsomedial SNc and dorsolateral VTA) and suppressed a $\mathrm{PITX}^{-}{ }^{-} / \mathrm{CALB}^{+}{ }^{+} / \mathrm{KCND}^{-}{ }^{-} / \mathrm{DAT}^{-}$identity [central and ventromedial VTA (Di Salvio et al., 2010a,b)] of the generated mdDA neurons.

The previous results prompted us to determine the amount of mdDA neurons expressing TH alone or together with CALB1 in the E18.5 $\mathrm{Dkk}^{-/-}$brain. The numbers of $\mathrm{TH}^{+} / \mathrm{CALB} 1^{-}$single- 

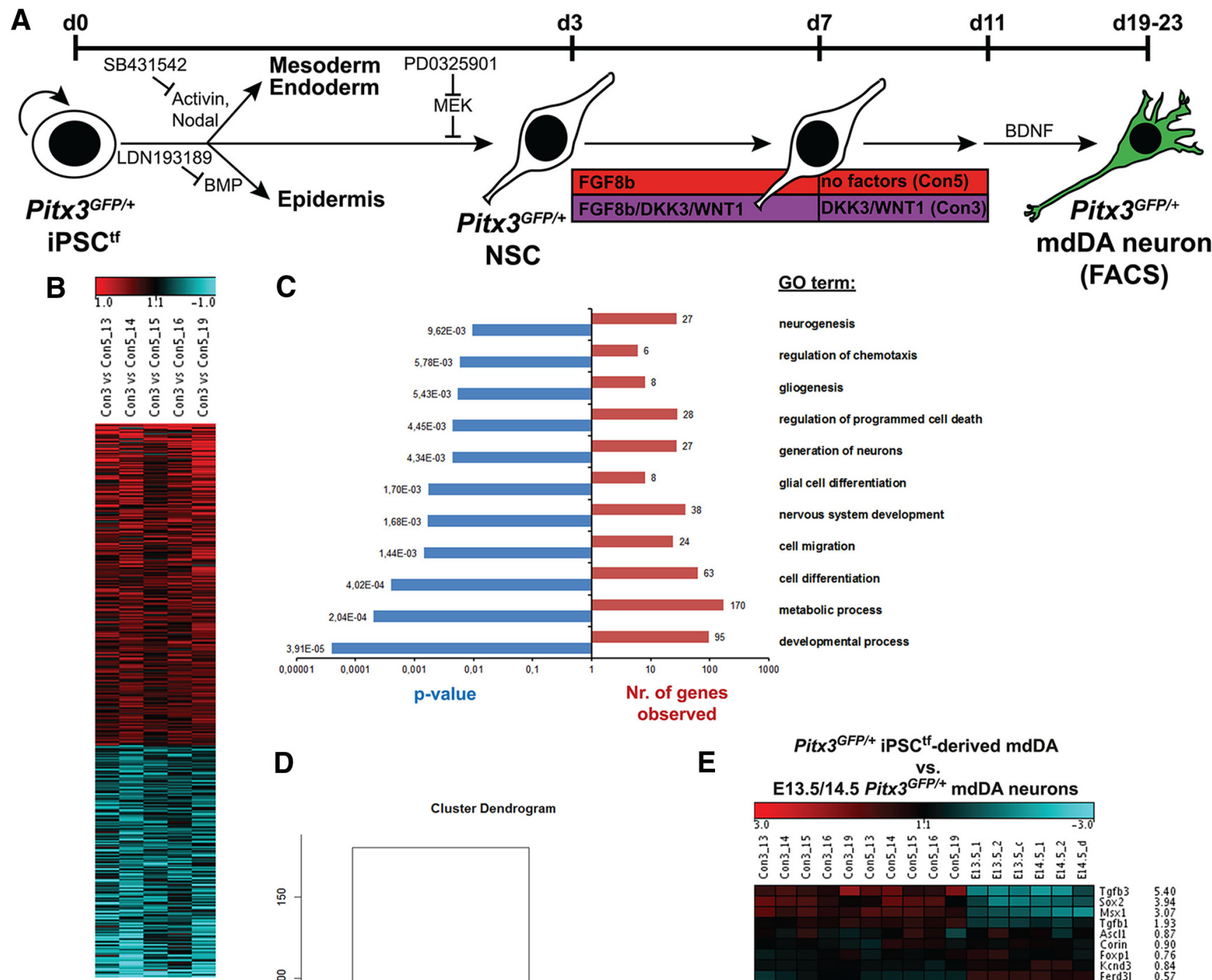

neurogenesis
regulation of chemotaxis
gliogenesis
regulation of programmed
generation of neurons
glial cell differentiation
nervous system development
cell migration
cell differentiation
metabolic process
developmental process

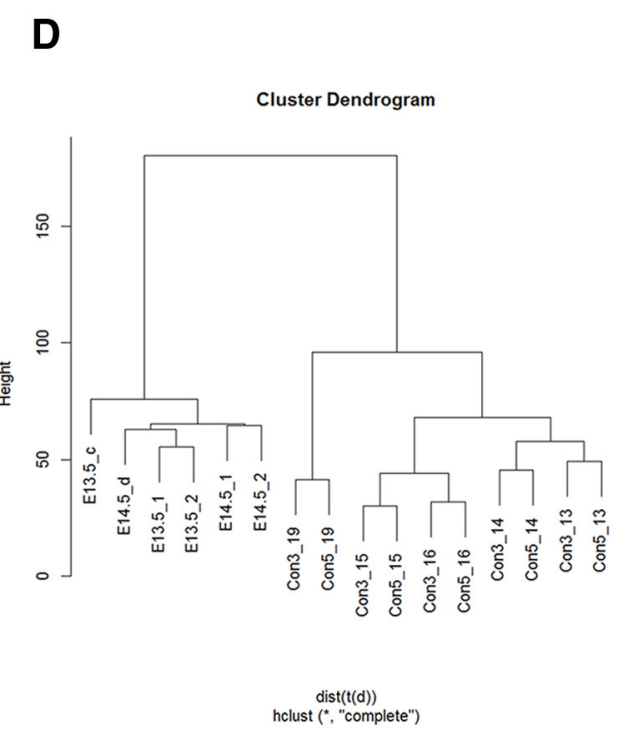

E
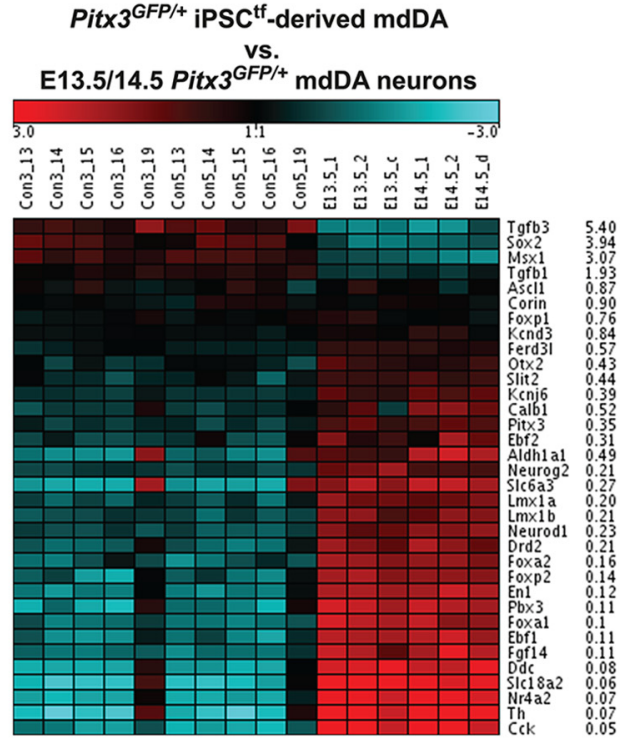

Figure 7. Global gene expression changes in DKK3/WNT1-treated versus untreated iPSC-derived Pitx ${ }^{G F P /+} \mathrm{mdDA}$ neurons. $\boldsymbol{A}$, Scheme of the monolayer protocol for the differentiation of Pitx $3^{G F P /+}$ iPSC ${ }^{\text {tf }}$ s with the conditions analyzed by microarray of FACS-sorted eGFP-expressing Pitx ${ }^{G F P /+}$ mdDA neurons (5 independent differentiation experiments: 13, 14, 15, 16, and 19). B, $C$, Heat map $(\boldsymbol{B})$ and $\mathrm{GO}$ term analysis $(\boldsymbol{C})$ of differentially regulated genes in the DKK3 + WNT1-treated iPSC-derived Pitx $3^{6 F P /+}$ mdDA neurons (Con3) relative to the untreated cells (Con5) (red, upregulated; blue, downregulated genes). D, Hierarchical clustering analysis of the global gene expression profiles of E13.5/E14.5 primary and DKK3 + WNT1-treated (Con3) or untreated (Con5) iPSC-derived Pit $3^{G F P /+}$ mdDA neurons. Clustering was done with the $R$ script hclust on probe sets with an average expression value $>50$ in at least one of the four groups. The ordinate in the hierarchical cluster dendrogram indicates the distance of samples. $\boldsymbol{E}$, Expression levels of selected mdDA progenitor- or mdDA neuron-specific genes in DKK3 + WNT1-treated (Con3) and untreated

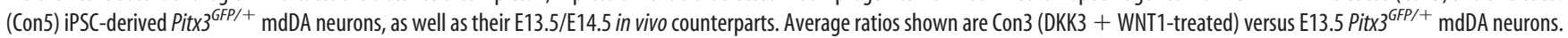

positive cells were increased significantly, whereas $\mathrm{TH}^{+} /$ CALB $1^{+}$double-positive cells were decreased significantly, in the rostrolateral $(\mathrm{SNc})$ but not caudomedial (VTA) domain of the mutant VM at E18.5 (Fig. $8 H-N$ ). In fact, the proportion of CALB $1^{+} / \mathrm{TH}^{+}$double-positive cells among all $\mathrm{TH}^{+}$neurons was reduced by $\sim 21 \%$ in the $D k k 3^{-1-} \mathrm{SNc}$ and remained unaffected in the $D k k 3^{-1-}$ VTA (data not shown), thus corresponding to a similar reduction $(-21 \%)$ of $\mathrm{PITX}^{+} / \mathrm{TH}^{+}$ double-positive mdDA neurons in the rostrolateral VM (PBP and dorsomedial $\mathrm{SNc}$ ) of the mutant embryos at this stage (Fig. $3 L$ ). This finding indicated that the lack of $D k k 3$ in the murine VM resulted in the general failure of an mdDA precursor subset to differentiate correctly into $\mathrm{TH}^{+} / \mathrm{PITX}^{+}$/ $\mathrm{LMX1A}^{+} / \mathrm{CALB}^{+}{ }^{+}$rostrolateral [dorsolateral VTA (PBP) and dorsomedial SNc] mdDA neurons and in the later loss of these neurons. 
A
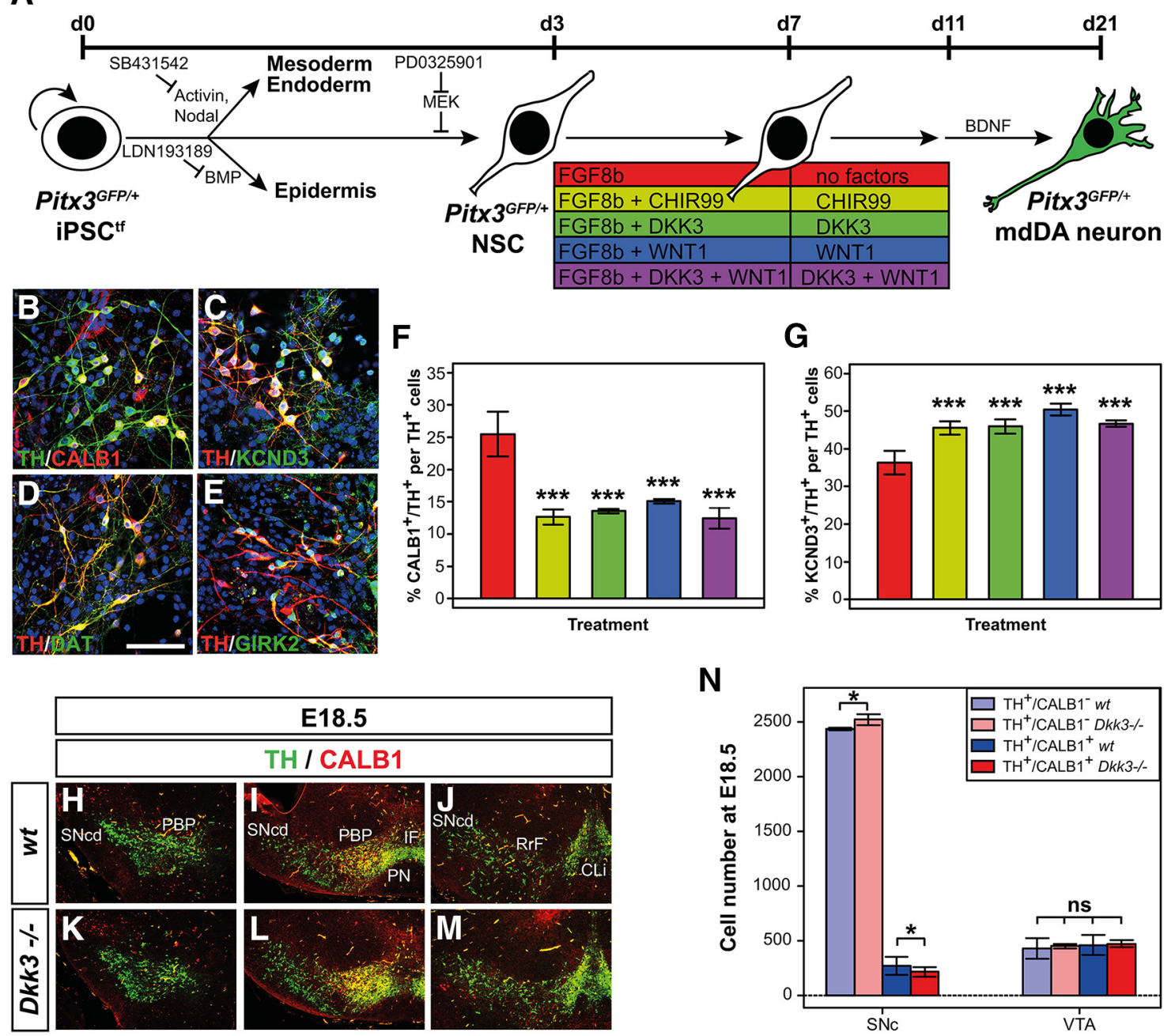

Figure 8. WNT/ $\beta$-catenin factor treatment promotes a rostrolateral (SNc) and suppresses a caudomedial (VTA) DA neuronal fate in differentiating PSCs in vitro. $A$, Scheme of the monolayer protocol for the differentiation of Pitx $3^{G F P /+}{ }_{\text {iPSC }}^{\text {tf }}$ s into mdDA neurons. $\boldsymbol{B}-\boldsymbol{E}$, Representative confocal close-up views of $\mathrm{TH}^{+}$(green) $/ \mathrm{CALB}^{+}(\mathrm{red})(\boldsymbol{B}), \mathrm{TH}^{+}(\mathrm{red}) / \mathrm{KCND}^{+}(\mathrm{green})(\boldsymbol{C}), \mathrm{TH}^{+}$ (red)/DAT ${ }^{+}$(green) (D), and TH ${ }^{+}$(red)/GIRK2 ${ }^{+}$(green) (E) cells after treatment of differentiating Pitx ${ }^{G F P /+}{ }^{+P S S C}{ }^{\text {tf }}$ s with DKK3 + WNT1. F, G, Quantification of the proportions of CALB1 ${ }^{+} /$TH $^{+}$ $(\boldsymbol{F})$ or $\mathrm{KCND3}^{+} / \mathrm{TH}^{+}(\boldsymbol{G})$ double-positive cells among all $\mathrm{TH}^{+}$cells after treatment of differentiating Pitx ${ }^{\mathrm{GFP} /+}{ }^{\mathrm{PPSC}} \mathrm{CH}^{\mathrm{tf}} \mathrm{s}$ with factor combinations as color coded in the scheme in $\boldsymbol{A}(n=3$ experiments/condition). Statistical testing for significance in $\boldsymbol{F}$ and $\boldsymbol{G}$ was done in relation to the untreated (only FGF8b-treated) cells. $\boldsymbol{H}-\boldsymbol{M}$, Representative close-up views of the VM on coronal sections (dorsal top) from WT $(\boldsymbol{H}-\boldsymbol{J})$ and $D k 3^{-I-}(\boldsymbol{K}-\boldsymbol{M})$ embryos at E18.5, immunostained for TH (green) and CALB1 (red). Sections were taken from rostral $(\boldsymbol{H}, \boldsymbol{K})$, intermediate $(\boldsymbol{I}, \boldsymbol{L})$, and caudal $(\boldsymbol{J}, \boldsymbol{M})$ levels of the VM. $\boldsymbol{N}$, Quantification of the amount of TH ${ }^{+} / \mathrm{CALB1}^{-}$single-positive and TH ${ }^{+} / \mathrm{CALB}^{+}$double-positive cells in the SNc and VTA of E18.5 WT or Dkk3 ${ }^{-/-}$embryos $(n=3$ embryos/genotype). ${ }^{*} p<0.05$ by the t test; ${ }^{* * *} p<0.001$ by one-way ANOVA relative to the FGF8b-treated cells; $n$ s, not significant in the $t$ test. CLi, Caudal linear nucleus; $\mathrm{FF}$, interfascicular nucleus; $\mathrm{PN}$, paranigral nucleus; RrF, retrorubral field; SNcd, Substantia nigra pars compacta dorsalis. Scale bar in $\boldsymbol{D}, 50 \mu \mathrm{m}$.

\section{Discussion}

We show that the secreted glycoprotein DKK3 was necessary and sufficient for the correct differentiation of an mdDA precursor subset into TH-, LMX1A-, and PITX3-expressing rostrolateral (PBP and dorsomedial SNc) mdDA neurons and their subsequent maintenance in the murine $\mathrm{VM}$ in vivo and primary VM cell cultures in vitro. We also show that the combined treatment of differentiating murine PSCs with DKK3 and WNT1 promoted their differentiation into mdDA neurons with molecular SNc DA neuron characteristics, indicating that DKK3 is an important factor for the in vivo and in vitro generation of these neurons.

The onset of Dkk3 transcription in the E11.5 mouse VM coincided with the extinction of $D k k 1$ and $D k k 2$ expression in this region of the brain (Monaghan et al., 1999; Ribeiro et al., 2011). DKK1 and DKK2 are known inhibitors of WNT/ $\beta$-catenin signaling (Niehrs, 2006), whereas DKK3 appears to modulate both positively and negatively this signaling pathway (Nakamura et al., 2007; Nakamura and Hackam, 2010; Das et al., 2013; Xiang et al., 2013). The sharp transition from $D k k 1 / 2$ to $D k k 3$ expression in the murine VM might thus mark the transition from an inactive to active $\mathrm{WNT} / \beta$-catenin signal transduction in neural progenitors and precursors located within the midbrain FP (Joksimovic et al., 2009). The onset of $D k k 3$ expression in the midbrain FP also coincided with the peak of mdDA neurogenesis between E10 and E11 in the mouse (Bayer et al., 1995; Bye et al., 2012) and suggested a requirement of DKK3 for the generation of these neurons. Despite its expression throughout the midbrain FP, Dkk3 was required only for the correct differentiation of a rostrolateral (PBP and dorsomedial SNc) mdDA neuronal subpopulation. Therefore, the responsiveness to DKK3 appears to be somehow restricted to the corresponding mdDA progenitor/precursor subset. The early loss of $L m \times 1 b$ and concomitantly of Wnt 1 expression in the mesencephalic lateral FP selectively affects mdDA 
neurogenesis from this lateral mdDA progenitor domain (Deng et al., 2011), suggesting that the restricted availability of the WNT1 ligand and of some of its downstream signaling effectors within this domain might be one limiting factor.

DKK3 was required specifically for the acquisition of PITX3 expression by a $\mathrm{TH}^{+}$ mdDA precursor subset during early mdDA neurogenesis (at E12.5; Fig. 9B) and for the later maintenance of PITX3, LMX1A, and TH expression in a rostrolateral (PBP and dorsomedial SNc) mdDA neuronal subset (at E14.5-E18.5; Fig. $9 C, D)$. This effect was also recapitulated in WT and $D k k 3^{-/-}$primary VM cells treated with DKK3 or BSA proteins in vitro. Although the overexpression of WNT1 in differentiating mouse ESCs induces the expression of Pitx 3 , this HD TF gene does not appear to be a direct target of WNT/ $\beta$-catenin signaling (Chung et al., 2009). WNT1 overexpression strongly induces the expression of $L m x 1 a$, and the LMX1A HD TF, in turn, appears to activate the transcription of Pitx3 in mouse ESCs (Chung et al., 2009). The Dkk3 ${ }^{-1-}$ embryos exhibited a similar defect in the acquisition of LMX1A expression by a $\mathrm{TH}^{+}$mdDA precursor subset as detected for PITX3, and DKK3 treatment of primary VM cells derived from WT or $D k k 3^{-/-}$embryos significantly increased or rescued, respectively, the transcription of Lmxla in these cells. Therefore, the defective differentiation of an mdDA precursor subset in the $D k k 3^{-/-}$embryos was very likely to be caused by their inability to induce and/or maintain the transcription of Lmx1a and consequently of Pitx3. Notably, the expression of LMX1B was not altered in the $D k k 3^{-/-}$embryos or DKK3treated VM cells, thus confirming previous evidence that $L m \times 1 b$ is not a direct target of WNT $1 / \beta$-catenin signaling (Chung et al., 2009; Joksimovic et al., 2009), and LMX1B alone is not sufficient for proper mdDA neuron differentiation (Yan et al., 2011).

The lack of $D k k 3$ in the murine VM or the treatment of primary VM cells with DKK3 protein did not affect the proliferation of $\mathrm{LMX} \mathrm{A}^{+}$mdDA and other VM neural progenitors or the initial generation of postmitotic LMX1A ${ }^{+}$mdDA precursors (at E11.5; Fig. 9A), indicating that DKK3 had an exclusive prodifferentiation function in developing mdDA precursors. Although the apoptotic death of $\mathrm{TH}^{+}$mdDA neurons and other VM cells did not appear to be altered in the absence of $D k k 3$, the treatment with DKK3 protein promoted the survival of primary VM cells in vitro. The loss of $\mathrm{TH}^{+}$rostrolateral (PBP and dorsomedial $\mathrm{SNc}$ ) mdDA neurons in the late gestational

A

E11.5

B

E12.5

C

E14.5

D

E18.5
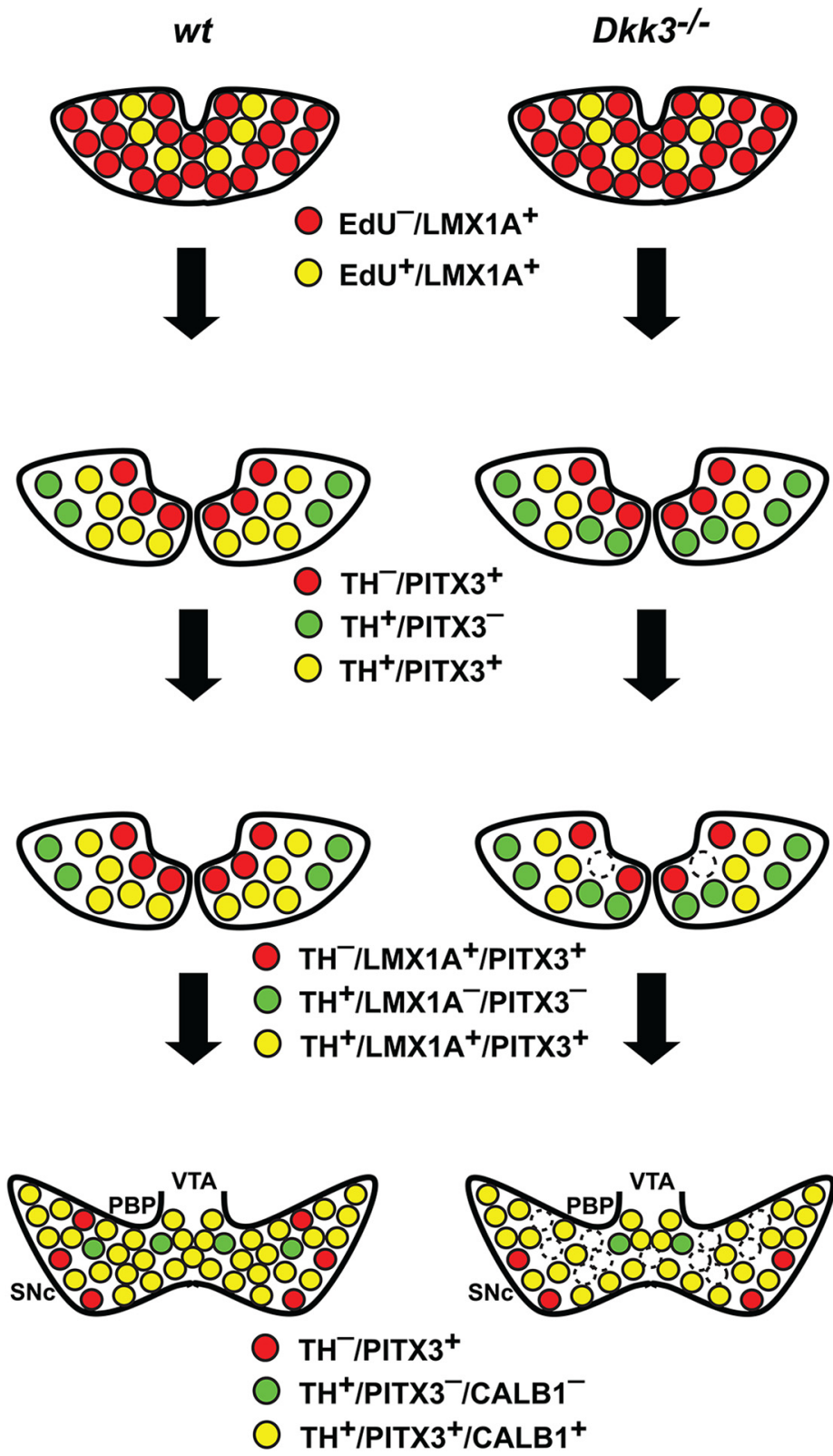

Figure 9. Selective differentiation defects and loss of a rostrolateral mdDA neuronal subset in $D k k 3^{-/-}$mice. $A-D$, Schematic coronal views of the rostrolateral mdDA domain in the VM of E11.5 (A), E12.5 (B), E14.5 (C), and E18.5 (D) WT and Dkk3 ${ }^{-/-}$ embryos, depicting the phenotypic defects of the mutant embryos. $\boldsymbol{A}$, Initially, at E11.5, the development of proliferating $\left(\mathrm{EdU}^{+}\right)$

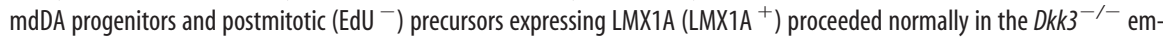
bryos. $B, A t E 12.5$, the first defects became apparent in the mutant embryos: the numbers of TH ${ }^{+} /$PITX3 ${ }^{-}$single-positive (green) cells were increased at the expense of $\mathrm{TH}^{+} / \mathrm{PITX} 3^{+}$double-positive (yellow) cells in the Dkk3 ${ }^{-/-}$VM, whereas $\mathrm{TH}^{-} / \mathrm{PITX} 3^{+}$ single-positive (red) cells remained unaffected at this stage. $C$, AtE14.5, the numbers of $\mathrm{TH}^{+} / \mathrm{LMX} \mathrm{A}^{-}$or $\mathrm{PITX} 3^{-}$single-positive (green) cells were still increased at the expense of $\mathrm{TH}^{+} / \mathrm{LMX1A}{ }^{+}$or PITX3 ${ }^{+}$double-positive (yellow) cells in the Dkk3${ }^{-/-} \mathrm{VM}_{\text {, }}$ but $\mathrm{TH}^{-} / \mathrm{LMX} \mathrm{A}^{+}$or PITX3 ${ }^{+}$single-positive (red) cells were also decreased at this stage in the mutants. $D$, Shortly before birth, at E18.5, $\mathrm{TH}^{-} / \mathrm{PITX}^{+}$(red), $\mathrm{TH}^{+} / \mathrm{PITX} 3^{-}$, or CALB1 ${ }^{-}$(green), and $\mathrm{TH}^{+/} \mathrm{PIX3}^{+}$or CALB1 ${ }^{+}$(yellow) single- and doublepositive cells were reduced by at least one-fifth $(\sim 20 \%)$ in the rostrolateral mdDA domain that comprises mostly the PBP and dorsomedial SNc. In vitro application of DKK3 protein rescued this selective differentiation defect in differentiating primary cells from the $D k 3^{-1-}$ VM and promoted the differentiation of PSCs into $\mathrm{TH}^{+} / \mathrm{PITX} 3^{+}$double-positive mdDA neurons with molecular SNC DA characteristics (CALB1 ${ }^{-} / \mathrm{KCND3}^{+} / \mathrm{DAT}^{+}$). Note that the coexpression of PITX3 and LMX1A or CALB1 in the same cell, as suggested by the scheme, has not been demonstrated in this work.
$D k k 3^{-/-}$embryos (at E18.5; Fig. 9D) might be an indirect consequence of the lack of PITX3 expression in these cells, because PITX3 is required for the transcription of $B d n f$ and the retinoic acid-synthesizing and DA metabolizing enzyme Aldh1a1 (aldehyde dehydrogenase family 1, subfamily A1) in 
SNc DA neurons and thus for their neurotrophic support and neuroprotection (Jacobs et al., 2007; Peng et al., 2011). Alternatively or in addition, DKK3 might act in an autocrine/paracrine manner as an anti-apoptotic and/or prosurvival factor in the mouse VM. There is ample evidence for such a cell typeand context-dependent anti-apoptotic/prosurvival function of DKK3 (Nakamura et al., 2007; Veeck and Dahl, 2012), which might be mediated by a distinct molecular pathway, such as TGF $\beta / S M A D$ signaling known to be required for mdDA neuron survival and to interact with DKK3 (Pinho and Niehrs, 2007; Hegarty et al., 2014).

Analogous to the primary VM cells, the treatment of differentiating mouse PSCs with DKK3 and WNT1 proteins promoted the acquisition of the $\mathrm{TH}^{+} / \mathrm{PITX}^{+} / \mathrm{NR} 4 \mathrm{~A} 2^{+}$mdDA phenotype by these cells. Remarkably, the treatment with $\mathrm{WNT} / \beta$-catenin signaling factors generally decreased the proportion of $\mathrm{TH}^{+}$cells coexpressing the predominant VTA DA neuron marker CALB1 (Di Salvio et al., 2010a; Fu et al., 2012) and increased the proportion of $\mathrm{TH}^{+}$cells coexpressing KCND3, a molecular marker of SNc DA neurons (Serôdio and Rudy, 1998; Liss et al., 2001). Therefore, our data support the idea that WNT/ $\beta$-catenin signaling is particularly important, at least in the mouse, for the generation of a rostrolateral (PBP and dorsomedial SNc) mdDA neuronal subpopulation in vivo and in vitro.

The treatment of differentiating Pit $\times 3^{G F P /+}$ iPSC $^{\text {tf }}$ s with DKK3 and WNT1 significantly upregulated or downregulated a number of genes implicated in developmental processes, such as cell differentiation and migration. Despite significant changes in the numbers of cells expressing the corresponding marker protein between the DKK3/WNT1-treated and untreated cultures, the transcript levels of mature mdDA neuronal markers generally (independent of treatment) appeared to be lower, whereas the transcript levels of PSC markers were increased, in the iPSC-derived relative to the primary (E13.5/E14.5) Pitx $3^{G F P /+}$ mdDA neurons. This suggested either that the iPSCderived $\mathrm{mdDA}$ neurons were still in a relatively immature state after 19-23 DIV compared with their in vivo counterparts or that several of the mdDA-specific genes were epigenetically silenced in these iPSC-derived neurons, as shown recently by Roessler et al. (2014) using an experimental approach very similar to ours. Furthermore, genes associated with the $\mathrm{WNT} / \beta$-catenin signaling pathway (either as components or direct/indirect targets of this pathway) were not regulated significantly between the DKK3/ WNT1-treated and untreated Pit $x 3^{G F P /+}$ mdDA neurons except for five downregulated genes, including Wnt4, Sox10, and Sox17. Interestingly, $W n t 4$ is a $\mathrm{WNT} / \beta$-catenin target gene that is repressed by the action of DKK3 (Das et al., 2013), whereas Sox10 and Sox 17 are two genes implicated in oligodendrocyte differentiation and SOX17 is a direct antagonist of WNT/ $\beta$-catenin signaling (Stolt et al., 2002; Sohn et al., 2006; Chew et al., 2011). These findings suggest that DKK3 might be required for the attenuation of active $\mathrm{WNT} / \beta$-catenin signaling in developing mdDA precursors to facilitate their differentiation into rostrolateral (PBP and dorsomedial SNc) mdDA neurons and to suppress alternative (e.g., oligodendroglial) cell fates. In fact, the treatment of differentiating murine PSCs with the strong activator of WNT/ $\beta$-catenin signaling CHIR99 rather decreased than increased the amount of $\mathrm{TH}^{+} / \mathrm{PITX}^{+}{ }^{+}$mdDA neurons generated in these cultures, although we used the same CHIR99 concentration that was reported previously to be much more potent than recombinant WNT1 protein for the induction of mdDA neurons from human PSCs (Kriks et al., 2011). Because the constitutive activation of $\mathrm{WNT} / \beta$-catenin signaling in mouse VM neural progenitors and precursors inhibits their differentiation into mature mdDA neurons in vivo (Joksimovic et al., 2009; Tang et al., 2010), our data also suggested that a difference between mice and humans might be the strength of the $\mathrm{WNT} / \beta$-catenin signal required for proper mdDA neuron generation. However, the molecular details of this signal transduction pathway and its potential species-specific differences remain to be elucidated.

Altogether, our results showed that DKK3 enhanced specifically the differentiation of mdDA precursors in vivo and PSCs or primary VM cells in vitro into rostrolateral (PBP and dorsomedial SNc) mdDA neurons, without affecting the proliferation and specification of their progenitors. Additionally, DKK3 promoted the survival of primary VM cells in vitro. These particular properties of DKK3, together with its known anti-tumorigenic effects (Veeck and Dahl, 2012), make it another prime candidate for the directed differentiation of PSCs into mdDA (SNc DA) neurons, which can be used in stem cell-based regenerative therapies and disease models of PD.

\section{References}

Andersson ER, Saltó C, Villaescusa JC, Cajanek L, Yang S, Bryjova L, Nagy II, Vainio SJ, Ramirez C, Bryja V, Arenas E (2013) Wnt5a cooperates with canonical Wnts to generate midbrain dopaminergic neurons in vivo and in stem cells. Proc Natl Acad Sci U S A 110:E602-E610. CrossRef Medline

Arenas E (2010) Towards stem cell replacement therapies for Parkinson's disease. Biochem Biophys Res Commun 396:152-156. CrossRef Medline

Bayer SA, Wills KV, Triarhou LC, Ghetti B (1995) Time of neuron origin and gradients of neurogenesis in midbrain dopaminergic neurons in the mouse. Exp Brain Res 105:191-199. Medline

Björklund A, Dunnett SB (2007) Dopamine neuron systems in the brain: an update. Trends Neurosci 30:194-202. CrossRef Medline

Blaess S, Corrales JD, Joyner AL (2006) Sonic hedgehog regulates Gli activator and repressor functions with spatial and temporal precision in the mid/hindbrain region. Development 133:1799-1809. CrossRef Medline

Blaess S, Bodea GO, Kabanova A, Chanet S, Mugniery E, Derouiche A, Stephen D, Joyner AL (2011) Temporal-spatial changes in Sonic Hedgehog expression and signaling reveal different potentials of ventral mesencephalic progenitors to populate distinct ventral midbrain nuclei. Neural Dev 6:29. CrossRef Medline

Bonilla S, Hall AC, Pinto L, Attardo A, Götz M, Huttner WB, Arenas E (2008) Identification of midbrain floor plate radial glia-like cells as dopaminergic progenitors. Glia 56:809-820. CrossRef Medline

Brodski C, Weisenhorn DM, Signore M, Sillaber I, Oesterheld M, Broccoli V, Acampora D, Simeone A, Wurst W (2003) Location and size of dopaminergic and serotonergic cell populations are controlled by the position of the midbrain-hindbrain organizer. J Neurosci 23:4199-4207. Medline

Bye CR, Thompson LH, Parish CL (2012) Birth dating of midbrain dopamine neurons identifies A9 enriched tissue for transplantation into parkinsonian mice. Exp Neurol 236:58-68. CrossRef Medline

Castelo-Branco G, Andersson ER, Minina E, Sousa KM, Ribeiro D, Kokubu C, Imai K, Prakash N, Wurst W, Arenas E (2010) Delayed dopaminergic neuron differentiation in Lrp6 mutant mice. Dev Dyn 239:211-221. CrossRef Medline

Chambers SM, Fasano CA, Papapetrou EP, Tomishima M, Sadelain M, Studer L (2009) Highly efficient neural conversion of human ES and iPS cells by dual inhibition of SMAD signaling. Nat Biotechnol 27:275-280. CrossRef Medline

Chew LJ, Shen W, Ming X, Senatorov VV Jr, Chen HL, Cheng Y, Hong E, Knoblach S, Gallo V (2011) SRY-box containing gene 17 regulates the Wnt/beta-catenin signaling pathway in oligodendrocyte progenitor cells. J Neurosci 31:13921-13935. CrossRef Medline

Chung S, Leung A, Han BS, Chang MY, Moon JI, Kim CH, Hong S, Pruszak J, Isacson O, Kim KS (2009) Wnt1-lmxla forms a novel autoregulatory loop and controls midbrain dopaminergic differentiation synergistically with the SHH-FoxA2 pathway. Cell Stem Cell 5:646-658. CrossRef Medline

Das DS, Wadhwa N, Kunj N, Sarda K, Pradhan BS, Majumdar SS (2013) Dickkopf homolog 3 (DKK3) plays a crucial role upstream of WNT/betaCATENIN signaling for Sertoli cell mediated regulation of spermatogenesis. PLoS One 8:e63603. CrossRef Medline 
Dauer W, Przedborski S (2003) Parkinson's disease: mechanisms and models. Neuron 39:889-909. CrossRef Medline

del Barco-Barrantes I, Montero-Pedrazuela A, Guadaño-Ferraz A, Obregon MJ, Martinez de Mena R, Gailus-Durner V, Fuchs H, Franz TJ, Kalaydjiev S, Klempt M, Hölter S, Rathkolb B, Reinhard C, Morreale de Escobar G, Bernal J, Busch DH, Wurst W, Wolf E, Schulz H, Shtrom S, et al. (2006) Generation and characterization of dickkopf3 mutant mice. Mol Cell Biol 26:2317-2326. CrossRef Medline

Deng Q, Andersson E, Hedlund E, Alekseenko Z, Coppola E, Panman L, Millonig JH, Brunet JF, Ericson J, Perlmann T (2011) Specific and integrated roles of Lmxla, Lmx1b and Phox2a in ventral midbrain development. Development 138:3399-3408. CrossRef Medline

Di Salvio M, Di Giovannantonio LG, Omodei D, Acampora D, Simeone A (2010a) Otx2 expression is restricted to dopaminergic neurons of the ventral tegmental area in the adult brain. Int J Dev Biol 54:939-945. CrossRef Medline

Di Salvio M, Di Giovannantonio LG, Acampora D, Prosperi R, Omodei D, Prakash N, Wurst W, Simeone A (2010b) Otx2 controls neuron subtype identity in ventral tegmental area and antagonizes vulnerability to MPTP. Nat Neurosci 13:1481-1488. CrossRef Medline

Fischer J, Beckervordersandforth R, Tripathi P, Steiner-Mezzadri A, Ninkovic J, Götz M (2011) Prospective isolation of adult neural stem cells from the mouse subependymal zone. Nat Protoc 6:1981-1989. CrossRef Medline

Friling S, Andersson E, Thompson LH, Jönsson ME, Hebsgaard JB, Nanou E, Alekseenko Z, Marklund U, Kjellander S, Volakakis N, Hovatta O, El Manira A, Björklund A, Perlmann T, Ericson J (2009) Efficient production of mesencephalic dopamine neurons by Lmx la expression in embryonic stem cells. Proc Natl Acad Sci U S A 106:7613-7618. CrossRef Medline

Fu Y, Yuan Y, Halliday G, Rusznák Z, Watson C, Paxinos G (2012) A cytoarchitectonic and chemoarchitectonic analysis of the dopamine cell groups in the substantia nigra, ventral tegmental area, and retrorubral field in the mouse. Brain Struct Funct 217:591-612. CrossRef Medline

Hegarty SV, Sullivan AM, O'Keeffe GW (2013) Midbrain dopaminergic neurons: a review of the molecular circuitry that regulates their development. Dev Biol 379:123-138. CrossRef Medline

Hegarty SV, Sullivan AM, O'Keeffe GW (2014) Roles for the TGFbeta superfamily in the development and survival of midbrain dopaminergic neurons. Mol Neurobiol 50:559-573. CrossRef Medline

Holm S (1979) A simple sequentially rejective multiple test procedure. Scand J Statistics 6:65-70.

Jacobs FM, Smits SM, Noorlander CW, von Oerthel L, van der Linden AJ, Burbach JP, Smidt MP (2007) Retinoic acid counteracts developmental defects in the substantia nigra caused by Pitx3 deficiency. Development 134:2673-2684. CrossRef Medline

Jaeger I, Arber C, Risner-Janiczek JR, Kuechler J, Pritzsche D, Chen IC, Naveenan T, Ungless MA, Li M (2011) Temporally controlled modulation of FGF/ERK signaling directs midbrain dopaminergic neural progenitor fate in mouse and human pluripotent stem cells. Development 138: 4363-4374. CrossRef Medline

Joksimovic M, Yun BA, Kittappa R, Anderegg AM, Chang WW, Taketo MM, McKay RD, Awatramani RB (2009) Wnt antagonism of Shh facilitates midbrain floor plate neurogenesis. Nat Neurosci 12:125-131. CrossRef Medline

Kele J, Simplicio N, Ferri AL, Mira H, Guillemot F, Arenas E, Ang SL (2006) Neurogenin 2 is required for the development of ventral midbrain dopaminergic neurons. Development 133:495-505. CrossRef Medline

Konstantoulas CJ, Parmar M, Li M (2010) FoxP1 promotes midbrain identity in embryonic stem cell-derived dopamine neurons by regulating Pitx3. J Neurochem 113:836-847. CrossRef Medline

Kriks S, Shim JW, Piao J, Ganat YM, Wakeman DR, Xie Z, Carrillo-Reid L, Auyeung G, Antonacci C, Buch A, Yang L, Beal MF, Surmeier DJ, Kordower JH, Tabar V, Studer L (2011) Dopamine neurons derived from human ES cells efficiently engraft in animal models of Parkinson's disease. Nature 480:547-551. CrossRef Medline

Lee SH, Lumelsky N, Studer L, Auerbach JM, McKay RD (2000) Efficient generation of midbrain and hindbrain neurons from mouse embryonic stem cells. Nat Biotechnol 18:675-679. CrossRef Medline

Liang CL, Sinton CM, German DC (1996) Midbrain dopaminergic neurons in the mouse: co-localization with Calbindin-D28K and calretinin. Neuroscience 75:523-533. CrossRef Medline
Li W, Li K, Wei W, Ding S (2013) Chemical approaches to stem cell biology and therapeutics. Cell Stem Cell 13:270-283. CrossRef Medline

Liss B, Franz O, Sewing S, Bruns R, Neuhoff H, Roeper J (2001) Tuning pacemaker frequency of individual dopaminergic neurons by $\mathrm{Kv} 4.3 \mathrm{~L}$ and KChip3.1 transcription. EMBO J 20:5715-5724. CrossRef Medline

Luk KC, Rymar VV, van den Munckhof P, Nicolau S, Steriade C, Bifsha P, Drouin J, Sadikot AF (2013) The transcription factor Pitx3 is expressed selectively in midbrain dopaminergic neurons susceptible to neurodegenerative stress. J Neurochem 125:932-943. CrossRef Medline

Monaghan AP, Kioschis P, Wu W, Zuniga A, Bock D, Poustka A, Delius H, Niehrs C (1999) Dickkopf genes are co-ordinately expressed in mesodermal lineages. Mech Dev 87:45-56. CrossRef Medline

Nakamura RE, Hackam AS (2010) Analysis of Dickkopf3 interactions with Wnt signaling receptors. Growth Factors 28:232-242. CrossRef Medline

Nakamura RE, Hunter DD, Yi H, Brunken WJ, Hackam AS (2007) Identification of two novel activities of the Wnt signaling regulator Dickkopf 3 and characterization of its expression in the mouse retina. BMC Cell Biol 8:52. CrossRef Medline

Niehrs C (2006) Function and biological roles of the Dickkopf family of Wnt modulators. Oncogene 25:7469-7481. CrossRef Medline

Ono Y, Nakatani T, Sakamoto Y, Mizuhara E, Minaki Y, Kumai M, Hamaguchi A, Nishimura M, Inoue Y, Hayashi H, Takahashi J, Imai T (2007) Differences in neurogenic potential in floor plate cells along an anteroposterior location: midbrain dopaminergic neurons originate from mesencephalic floor plate cells. Development 134:3213-3225. CrossRef Medline

Oshimori N, Fuchs E (2012) The harmonies played by TGF-beta in stem cell biology. Cell Stem Cell 11:751-764. CrossRef Medline

Peng C, Aron L, Klein R, Li M, Wurst W, Prakash N, Le W (2011) Pitx3 is a critical mediator of GDNF-induced BDNF expression in nigrostriatal dopaminergic neurons. J Neurosci 31:12802-12815. CrossRef Medline

Perez-Balaguer A, Puelles E, Wurst W, Martinez S (2009) Shh dependent and independent maintenance of basal midbrain. Mech Dev 126:301313. CrossRef Medline

Pertek A, Meier F, Irmler M, Beckers J, Skylaki S, Endele M, Wurst W, Prakash N, Kühn R (2014) Simple derivation of transgene-free iPS cells by a dual recombinase approach. Mol Biotechnol 56:697-713. CrossRef Medline

Pinho S, Niehrs C (2007) Dkk3 is required for TGF-beta signaling during Xenopus mesoderm induction. Differentiation 75:957-967. CrossRef Medline

Prakash N, Brodski C, Naserke T, Puelles E, Gogoi R, Hall A, Panhuysen M, Echevarria D, Sussel L, Weisenhorn DM, Martinez S, Arenas E, Simeone A, Wurst W (2006) A Wnt1-regulated genetic network controls the identity and fate of midbrain-dopaminergic progenitors in vivo. Development 133:89-98. CrossRef Medline

Pruszak J, Just L, Isacson O, Nikkhah G (2009) Isolation and culture of ventral mesencephalic precursor cells and dopaminergic neurons from rodent brains. Curr Protoc Stem Cell Biol Chapter 2:Unit 2D.5. CrossRef Medline

Puelles E, Annino A, Tuorto F, Usiello A, Acampora D, Czerny T, Brodski C, Ang SL, Wurst W, Simeone A (2004) Otx2 regulates the extent, identity and fate of neuronal progenitor domains in the ventral midbrain. Development 131:2037-2048. CrossRef Medline

Rainer J, Sanchez-Cabo F, Stocker G, Sturn A, Trajanoski Z (2006) CARMAweb: comprehensive R- and bioconductor-based web service for microarray data analysis. Nucleic Acids Res 34:W498-W503. CrossRef Medline

Reyes S, Fu Y, Double K, Thompson L, Kirik D, Paxinos G, Halliday GM (2012) GIRK2 expression in dopamine neurons of the substantia nigra and ventral tegmental area. J Comp Neurol 520:2591-2607. CrossRef Medline

Ribeiro D, Ellwanger K, Glagow D, Theofilopoulos S, Corsini NS, MartinVillalba A, Niehrs C, Arenas E (2011) Dkk1 regulates ventral midbrain dopaminergic differentiation and morphogenesis. PLoS One 6:e15786. CrossRef Medline

Roessler R, Smallwood SA, Veenvliet JV, Pechlivanoglou P, Peng SP, Chakrabarty K, Groot-Koerkamp MJ, Pasterkamp RJ, Wesseling E, Kelsey G, Boddeke E, Smidt MP, Copray S (2014) Detailed analysis of the genetic and epigenetic signatures of iPSC-derived mesodiencephalic dopaminergic neurons. Stem Cell Rep 2:520-533. CrossRef Medline

Sarkar A, Hochedlinger K (2013) The sox family of transcription factors: versatile regulators of stem and progenitor cell fate. Cell Stem Cell 12: 15-30. CrossRef Medline 
Schultz W (2007) Multiple dopamine functions at different time courses. Annu Rev Neurosci 30:259-288. CrossRef Medline

Serôdio P, Rudy B (1998) Differential expression of Kv4 K+ channel subunits mediating subthreshold transient $\mathrm{K}+$ (A-type) currents in rat brain. J Neurophysiol 79:1081-1091. Medline

Smidt MP, Burbach JP (2007) How to make a mesodiencephalic dopaminergic neuron. Nat Rev Neurosci 8:21-32. CrossRef Medline

Sohn J, Natale J, Chew LJ, Belachew S, Cheng Y, Aguirre A, Lytle J, NaitOumesmar B, Kerninon C, Kanai-Azuma M, Kanai Y, Gallo V (2006) Identification of Sox17 as a transcription factor that regulates oligodendrocyte development. J Neurosci 26:9722-9735. CrossRef Medline

Stolt CC, Rehberg S, Ader M, Lommes P, Riethmacher D, Schachner M, Bartsch U, Wegner M (2002) Terminal differentiation of myelinforming oligodendrocytes depends on the transcription factor Sox10. Genes Dev 16:165-170. CrossRef Medline

Stuebner S, Faus-Kessler T, Fischer T, Wurst W, Prakash N (2010) Fzd3 and Fzd6 deficiency results in a severe midbrain morphogenesis defect. Dev Dyn 239:246-260. CrossRef Medline

Tabar V, Studer L (2014) Pluripotent stem cells in regenerative medicine: challenges and recent progress. Nat Rev Genet 15:82-92. CrossRef Medline

Tang M, Miyamoto Y, Huang EJ (2009) Multiple roles of beta-catenin in controlling the neurogenic niche for midbrain dopamine neurons. Development 136:2027-2038. CrossRef Medline

Tang M, Villaescusa JC, Luo SX, Guitarte C, Lei S, Miyamoto Y, Taketo MM,
Arenas E, Huang EJ (2010) Interactions of Wnt/beta-catenin signaling and sonic hedgehog regulate the neurogenesis of ventral midbrain dopamine neurons. J Neurosci 30:9280-9291. CrossRef Medline

Veeck J, Dahl E (2012) Targeting the Wnt pathway in cancer: the emerging role of Dickkopf-3. Biochim Biophys Acta 1825:18-28. CrossRef Medline

Wurst W, Bally-Cuif L (2001) Neural plate patterning: upstream and downstream of the isthmic organizer. Nat Rev Neurosci 2:99-108. CrossRef Medline

Xiang T, Li L, Yin X, Zhong L, Peng W, Qiu Z, Ren G, Tao Q (2013) Epigenetic silencing of the WNT antagonist Dickkopf 3 disrupts normal Wnt/ beta-catenin signalling and apoptosis regulation in breast cancer cells. J Cell Mol Med 17:1236-1246. CrossRef Medline

Yan CH, Levesque M, Claxton S, Johnson RL, Ang SL (2011) Lmxla and $1 \mathrm{mx} 1 \mathrm{~b}$ function cooperatively to regulate proliferation, specification, and differentiation of midbrain dopaminergic progenitors. J Neurosci 31: 12413-12425. CrossRef Medline

Yu DX, Marchetto MC, Gage FH (2013) Therapeutic translation of iPSCs for treating neurological disease. Cell Stem Cell 12:678-688. CrossRef Medline

Zhao S, Maxwell S, Jimenez-Beristain A, Vives J, Kuehner E, Zhao J, O’Brien C, de Felipe C, Semina E, Li M (2004) Generation of embryonic stem cells and transgenic mice expressing green fluorescence protein in midbrain dopaminergic neurons. Eur J Neurosci 19:1133-1140. CrossRef Medline 